\title{
How Communication Improves Efficiency in Bargaining: Reconciling Theory with Evidence
}

Citation for published version (APA):

Saran, R. R. S. (2009). How Communication Improves Efficiency in Bargaining: Reconciling Theory with Evidence. Maastricht University School of Business and Economics. METEOR Research Memorandum No. 022 https://doi.org/10.26481/umamet.2009022

Document status and date:

Published: 01/01/2009

DOI:

10.26481/umamet.2009022

Document Version:

Publisher's PDF, also known as Version of record

\section{Please check the document version of this publication:}

- A submitted manuscript is the version of the article upon submission and before peer-review. There can be important differences between the submitted version and the official published version of record.

People interested in the research are advised to contact the author for the final version of the publication, or visit the DOI to the publisher's website.

- The final author version and the galley proof are versions of the publication after peer review.

- The final published version features the final layout of the paper including the volume, issue and page numbers.

Link to publication

\footnotetext{
General rights rights.

- You may freely distribute the URL identifying the publication in the public portal. please follow below link for the End User Agreement:

www.umlib.nl/taverne-license

Take down policy

If you believe that this document breaches copyright please contact us at:

repository@maastrichtuniversity.nl

providing details and we will investigate your claim.
}

Copyright and moral rights for the publications made accessible in the public portal are retained by the authors and/or other copyright owners and it is a condition of accessing publications that users recognise and abide by the legal requirements associated with these

- Users may download and print one copy of any publication from the public portal for the purpose of private study or research.

- You may not further distribute the material or use it for any profit-making activity or commercial gain

If the publication is distributed under the terms of Article $25 \mathrm{fa}$ of the Dutch Copyright Act, indicated by the "Taverne" license above, 


\title{
Maastricht University
}

\author{
Rene Saran \\ How Communication I mproves \\ Efficiency in Bargaining: Reconciling \\ Theory with Evidence
}

$\mathrm{RM} / 09 / 022$

\section{METEOR}

Faculty of Economics and Business Administration Maastricht Research School of Economics

of Technology and Organization

\section{P.O. Box 616}

NL - 6200 MD Maastricht

The Netherlands 


\title{
How Communication Improves Efficiency in Bargaining: Reconciling Theory with Evidence*
}

\author{
Rene $\operatorname{Saran}^{\dagger}$ \\ Maastricht University, Maastricht, The Netherlands
}

May 15, 2009

\begin{abstract}
Previous theoretical literature proved the existence of an upper bound on efficiency in bilateral bargaining. In contrast, experiments consistently find players obtaining higher efficiency than the upper bound if they are allowed to communicate before the $\frac{1}{2}$-double auction. We bridge this gap between theory and experiments by introducing an $\epsilon$ proportion of behavioral-type players who always truthfully reveal their valuations and declare a keenness to trade before bidding in the $\frac{1}{2}$-double auction. Preplay communication is used by the strategic types to communicate their "tougher" bargaining position, forcing the behavioral types to adopt a "weaker" position. This further induces the strategic types to decrease the shading/exaggeration in the announcement of their valuations lest they miss the chance to trade with the "weaker" behavioral types. As a result, for any $\epsilon>0$, the efficiency in equilibrium is greater than the upper bound.
\end{abstract}

Keywords: Bargaining; Behavioral Type; Communication; Double Auction; Efficiency; Incomplete Information

JEL: C78; D82

${ }^{*}$ This paper is based on Chapter 2 of my Ph.D dissertation (Brown University, 2007), which was circulated under the title "Bargaining with Behavioral Player: Strategic Deception and More Trade". I am indebted to my advisor Roberto Serrano for his guidance and suggestions throughout the project. I also thank Pedro Dal Bó, Ronald Peteers and J. Philipp Reiß for their comments and suggestions, and ISI (Delhi) for its hospitality.

${ }^{\dagger}$ Email address: r.saran@maastrichtuniversity.nl; Tel: +31-43-3883763; Fax: +31-43-3884878 


\section{Introduction}

Bilateral bargaining encounters are ubiquitous in markets. A particular model of bilateral bargaining that has been extensively studied in the literature is the $\frac{1}{2}$-double auction. ${ }^{1}$ In the $\frac{1}{2}$-double auction, the traders simultaneously submit sealed bids for the object and trade takes place if and only if the buyer's bid exceeds the seller's bid at a price equal to the average of the two bids. Chatterjee and Samuelson (1983) find a linear-strategy equilibrium of the $\frac{1}{2}$-double auction when the valuations of the players are distributed independently and uniformly on $[0,1]$ (henceforth termed CS equilibrium). However, the players' incentives to misrepresent their private information imply that the CS equilibrium is not first-best in terms of efficiency, that is, sometimes the players will not trade even though trade is desirable - in fact, first-best cannot be obtained in equilibrium of any mechanism (Myerson and Satterthwaite (1983)). ${ }^{2}$

Bargaining is, however, often preceded by communication among the players. Farrell and Gibbons (1989) and Mathews and Postlewaite (1989) show that communication before bidding in a double auction increases the set of equilibrium outcomes. However, none of these additional equilibria outperform the CS equilibrium in terms of efficiency. In fact, Myerson and Satterthwaite (1983) prove that the CS equilibrium is second-best, that is, it achieves both the highest ex-ante gains from trade and the highest ex-ante probability of trade relative to any equilibrium outcome of any bilateral bargaining mechanism that the players can use. ${ }^{3}$ In particular, this means that even if the players communicate in any form (simultaneously or sequentially) before they bid in the $\frac{1}{2}$-double auction, they cannot attain higher ex-ante gains from trade or ex-ante probability of trade than that in the CS equilibrium. Hence, although preplay communication increases the set of equilibrium outcomes of the double auction, it cannot improve efficiency over the best equilibrium outcome without communication.

In a sharp contrast to these theoretical results, experimental studies by Valley et al. (2002) and McGinn et al. (2003) on the $\frac{1}{2}$-double auction with uniform distribution of valuations find that when the players are allowed to communicate freely (either in written or verbal form) before playing the double auction, they are able to trade much more often and hence,

\footnotetext{
${ }^{1}$ For theoretical analysis see Chatterjee and Samuelson (1983), Williams (1987), Farrell and Gibbons (1989), Mathews and Postlewaite (1989), Leininger et al. (1989) and Satterthwaite and Williams (1989). Radner and Schotter (1989), Valley et al. (2002) and McGinn et al. (2003) conduct experiments on the $\frac{1}{2}$-double auction.

${ }^{2}$ See chapter 5 in Osborne and Rubinstein (1990), Binmore et al. (1992), Kennan and Wilson (1993), Ausubel et al. (2002) and Serrano (2008) for surveys on bargaining with incomplete information.

${ }^{3}$ This is not true for generic distributions of valuations as shown by Satterthwaite and Williams (1989).
} 
attain much higher ex-ante gains from trade and ex-ante probability of trade than the CS equilibrium. ${ }^{4}$ For instance, Valley et al. (2002, Table 1) report that when the players were not allowed to communicate, trade occurred in only $54 \%$ of the cases with positive gains; whereas when the players communicated face-to-face before the double auction, trade occurred in $85 \%$ of the cases with positive gains. In this paper, we are interested in bridging this gap between theory and experimental evidence. ${ }^{5}$

Valley et al. (2002) and McGinn et al. (2003) find that improved efficiency in communication treatments is driven by the choice of the following three dyadic strategies by the players (i) coordination on a single price (ii) mutual revelation of valuations and (iii) mutual bidding of valuations. For instance, Valley et al. (2002) find that in the communication treatments, out of 129 pairs of players with positive gains from trade, 73 coordinated on a single price and 8 mutually revealed their valuations. In their communication treatments, McGinn et al. (2003) find that out of 50 pairs with positive gains from trade, 21 coordinated on a single price, 13 mutually revealed their valuations and 10 mutually bid their valuations. These findings of dyadic behavior in bargaining with preplay communication prompt Valley et al. (2002, p. 151) to conclude:

Bargaining often occurs with some communication between the parties. If, as our findings suggest, this communication substantially changes the strategies chosen by the players, then the critical consequences of communication - coordination and honest revelation - need to be considered in future theories of bargaining.

Mathews and Postlewaite (1989) have shown that in equilibrium, preplay communication can be used by different valuation-type pairs of the players to coordinate on different singleprice equilibria in the double auction. However, as mentioned above, this coordination does not improve efficiency over the CS equilibrium. In light of the experimental evidence, this suggests that the missing element in theoretical models is "honest revelation". Theoretical models assume that all players are strategic who misrepresent private information whenever they have the incentive to do so. ${ }^{6}$ Whereas evidence suggests that players are averse to lying. For instance, McGinn et al. (2003) find that over $50 \%$ of the players honestly revealed

\footnotetext{
${ }^{4}$ In their experiment, Radner and Schotter (1989) also find that face-to-face negotiations outperform the CS equilibrium of the $\frac{1}{2}$-double auction in terms of efficiency. However, in the face-to-face negotiations, players both communicated and bargained at the same time. We are instead interested in preplay communication.

${ }^{5}$ There is also evidence that communication improves efficiency in games other than double auctions. For instance, see Hoffman and Spitzer (1982) and Valley et al. (1998).

${ }^{6}$ For exceptions see Sobel (1985), Dasgupta (1988), Severinov and Deneckere (2006) and Saran (2008). Nonstrategic behavior other than honesty has also been studied in Kreps et al. (1982), Kreps and Wilson (1982), Milgrom and Roberts (1982) and Abreu and Gul (2000).
} 
their valuations. ${ }^{7}$ We show that relaxing the assumption of strategic behavior and instead assuming that an $\epsilon>0$ proportion of the population is honest in communication is sufficient to obtain a higher efficiency than the CS equilibrium in an equilibrium of a $\frac{1}{2}$-double auction with preplay communication.

The bargaining model is a $\frac{1}{2}$-double auction preceded by a single simultaneous round of communication. In the communication stage, each player (a buyer and a seller) simultaneously sends two messages. As a first message, a player announces her valuation (not necessarily truthfully). As a second message, a player declares either that she is keen to trade or that she is not keen trade. Each player can have one of the two dispositions, strategic type or behavioral type. The probability that a player is behavioral type is $\epsilon$. The valuations of both the players irrespective of their disposition types are distributed uniformly on $[0,1]$.

A behavioral-type player is nonstrategic only in communication. In the communication stage, a behavioral type honestly reveals her valuation and declares that she is keen to trade (it is not necessary that the behavioral types announce "keen to trade"; see Section 4). ${ }^{8}$ No further assumption is made about the behavior of the behavioral types in the double auction. Thus, the behavioral types play sequentially rational strategies in the double auction.

We find a fully separating equilibrium of the game. Strategic-type players use the communication stage to both signal their valuations and their intention to adopt a "tougher" bargaining position in the double auction. To signal her valuation, a strategic-type player announces a unique shaded/exaggerated valuation. The amount of shading/exaggeration is, however, constrained since players walk away from trade in case the announced valuations suggest that there are no gains from trade. During preplay communication, the strategic types also announce that they are not keen to trade. In equilibrium, the player who announces that she is not keen to trade takes a "tougher" position in the double auction conceding no gains from trade suggested by the announced valuations if the other player is keen to trade and at most half the gains from trade suggested by the announced valuations if the other player is also not keen to trade. In contrast, the player who announces that she is keen to trade takes a "weaker" position in the double auction conceding all the gains from trade suggested by the announced valuations if the other player is not keen to trade and at most half the gains from trade suggested by the announced valuations if the other player announces that she is also keen to trade. Therefore, by announcing that she is not keen to trade, a strategic-type player signals her intention to adopt a "tougher" bargaining position

\footnotetext{
${ }^{7}$ For more evidence on aversion to lying, see Lundquist et al. (2009).

${ }^{8}$ That is why we purposely refrain from calling preplay communication "cheap talk"; it is not "costless" for behavioral types to send any message.
} 
in the double auction. This separates a strategic type from the behavioral types who in turn must accept a "weaker" position in the double auction (since they cannot imitate strategic types in order to signal a "tougher" position). Hence, the messages of keen and not keen in the communication stage help in coordinating the bargaining positions of different disposition types of the players in the double auction. An outcome of this coordination is that in equilibrium, players coordinate on a single price in the double auction, which is determined by both the announced valuations and the bargaining positions signaled by each of them.

Our main result is that for any $\epsilon>0$ and for any ex-post realization of disposition types, the trading region in our fully separating equilibrium is a strict superset of the trading region in the CS equilibrium. In particular, this means that for any $\epsilon>0$, the ex-ante gains from trade and the ex-ante probability of trade in our equilibrium is strictly higher than the CS equilibrium. As $\epsilon$ increases, then irrespective of the disposition types of the players, the trading regions inch closer to the first-best trading region. Thus both the ex-ante gains from trade and the ex-ante probability of trade in our equilibrium increase as $\epsilon$ increases.

Like Mathews and Postlewaite (1989), different type pairs of the players use preplay communication to coordinate on different single-price equilibria in the double auction; yet they are able to trade more often than the CS equilibrium. Intuitively, the presence of behavioral types who honestly reveal their valuations and accept a "weaker" position in the double auction induces the strategic types to reduce the shading/exaggeration in the announcements of their valuations lest they loose the chance to trade with the behavioral types at a "good" price. Thus, our analysis suggests that preplay communication improves efficiency not just due to coordination on single price and honest revelation by a proportion of the population; the strategic response of using preplay communication to signal their "tougher" bargaining position against such honest players is also an important factor.

We outline the model, solve for the equilibrium and present comparative statics with respect to $\epsilon$ in Section 2. We compare the equilibrium outcome with the CS equilibrium in Section 3. In Section 4, we discuss the robustness of the results. We conclude in Section 5 and collect all the proofs in Section 6.

\section{Model}

There are two players, a buyer (denoted by $b$ ) and a seller (denoted by $s$ ). The seller owns an indivisible object that she would like to trade with the buyer.

Each player $i$ can have one of the two dispositions $\left(d_{i}\right)$, behavioral (denoted by $b h$ ) 
and strategic (denoted by st). The probability that a player is a behavioral type is $\epsilon \epsilon$ $(0,1)$, which is independent of the valuation and disposition types of the other player. The valuations of both disposition types of a player are distributed uniformly on $[0,1]$ and are also independent of the other player's valuation and disposition. Each player privately knows her type $\left(v_{i}, d_{i}\right)$ but does not know the true type of the other player. The probability $\epsilon$ and the distributions of valuations of the players are common knowledge.

Denote the valuations of the buyer and seller by $v_{b}$ and $v_{s}$, respectively. If the object is traded at price $p$, then the buyer's payoff is $v_{b}-p$ while the seller's payoff is $p-v_{s}$. Both players get a payoff of 0 if the good is not traded.

The players trade using the $\frac{1}{2}$-double auction with a preplay communication stage. In the communication stage, the players simultaneously make two announcements. Firstly, a player announces her valuation in $[0,1]$. Secondly, a player announces whether she is keen $(K)$ or not keen $(N K)$ to trade. Thus, each player $i$ sends a pair of messages $\left(m_{i}^{1}, m_{i}^{2}\right)$ in the communication stage, where $m_{i}^{1} \in[0,1]$ and $m_{i}^{2} \in\{K, N K\}$. After the communication stage, the players play the $\frac{1}{2}$-double auction. In the $\frac{1}{2}$-double auction, both players simultaneously bid for the object. The object is traded if and only if the buyer's bid $t_{b}$ is at least as high as the seller's bid $t_{s}$ at a price equal to the average of both the bids.

Behavioral types act nonstrategically only during preplay communication. In the communication stage, a behavioral-type player announces her true valuation and that she is keen to trade. However, the behavioral types are strategic in the $\frac{1}{2}$-double auction that follows the communication stage. That is, in the double auction, like a strategic type, a behavioraltype player takes into account the information from the communication stage to update her beliefs and plays a best-response to the other player's strategy.

The equilibrium concept we use is perfect Bayesian equilibrium (see Fudenberg and Tirole (1991)), modified to incorporate the nonstrategic behavior of the behavioral types in the communication stage. In our model, a perfect Bayesian equilibrium is a set of strategies and beliefs such that (i) in any continuation game, the beliefs of the players (both strategic and behavioral type) are updated using Bayes rule (if possible) and, given those beliefs, the strategies of the players (both strategic and behavioral type) are a Bayesian equilibrium (irrespective of whether the continuation game is on or off-the-equilibrium path) and (ii) given the strategies and beliefs in the continuation games, strategies of the strategic-type players in the communication stage are a Bayesian equilibrium of the reduced game in which the players' payoffs after any pair of announcements are given by their expected payoffs in the corresponding continuation game. 
The next proposition specifies a fully separating symmetric equilibrium of the game. ${ }^{9}$ Our proof is such that we do not have to specify (i) the belief of any type of player $i$ in any off-the-equilibrium path continuation game $\left[\left(m_{b}^{1}, m_{b}^{2}\right),\left(m_{s}^{1}, m_{s}^{2}\right)\right]$ (i.e., the continuation game after such a pair of announcements) such that the message $\left(m_{j}^{1}, m_{j}^{2}\right)$ is not used by any type of player $j$ in equilibrium and (ii) the strategy of any type of any player $i$ in any continuation game $\left[\left(m_{b}^{1}, m_{b}^{2}\right),\left(m_{s}^{1}, m_{s}^{2}\right)\right]$ such that both messages $\left(m_{b}^{1}, m_{b}^{2}\right)$ and $\left(m_{s}^{1}, m_{s}^{2}\right)$ are used respectively by some type of buyer and seller in equilibrium but $\left(m_{i}^{1}, m_{i}^{2}\right)$ is not an equilibrium message of that type of player $i$.

Proposition 1. Define $\alpha(\epsilon)=\frac{5 \epsilon-3+\sqrt{(5 \epsilon-3)^{2}+16 \epsilon(1-\epsilon)}}{4 \epsilon}, \beta(\epsilon)=\frac{(1-\epsilon)^{2}}{[4(1-\epsilon)+2 \epsilon \alpha(\epsilon)][3(1-\epsilon)+2 \epsilon \alpha(\epsilon)]}$ and $\gamma(\epsilon)=\frac{1-\epsilon}{4(1-\epsilon)+2 \epsilon \alpha(\epsilon)}$. The following strategies and beliefs are a perfect Bayesian equilibrium:

- Strategies:

1. For the behavioral-type buyer of valuation $v_{b}$ :

(a) In the communication stage, announce $m_{b}^{1}=v_{b}$ and $m_{b}^{2}=K$.

(b) In the double-auction stage,

$\diamond$ if $\left(m_{b}^{1}, m_{b}^{2}\right)=\left(v_{b}, K\right),\left(m_{s}^{1}, m_{s}^{2}\right)$ is a message used in equilibrium by some type of the seller and

* if $m_{s}^{1}>m_{b}^{1}$, then bid 0 .

* if $m_{s}^{1} \leq m_{b}^{1}$ and $m_{s}^{2}=K$, then bid $\frac{1}{2}\left(m_{b}^{1}+m_{s}^{1}\right)$.

* if $m_{s}^{1} \leq m_{b}^{1}$ and $m_{s}^{2}=N K$, then bid $m_{b}^{1}$.

$\diamond$ if for any player $i$, the message $\left(m_{i}^{1}, m_{i}^{2}\right)$ is not used in equilibrium by any type of player $i$, then bid 0 .

2. For the strategic-type buyer of valuation $v_{b}$ :

(a) In the communication stage, announce $m_{b}^{2}=N K$ and

$$
m_{b}^{1}\left(v_{b}\right) \equiv\left\{\begin{array}{cl}
\alpha(\epsilon) v_{b}+\beta(\epsilon) & \text { if } v_{b} \geq \gamma(\epsilon) \\
v_{b} & \text { if } v_{b}<\gamma(\epsilon)
\end{array}\right.
$$

(b) In the double-auction stage,

\footnotetext{
${ }^{9}$ The equilibrium is symmetric in the sense that if the buyer and seller have the same disposition, then (i) in the communication stage, they announce the same keen or not keen to trade message and the valuation announced by the buyer of valuation $v$ is equal to 1 minus the valuation announced by the seller of valuation $1-v$ and (ii) in the double-auction stage, they demand the same share of the surplus suggested by the announced valuations from their opponent.
} 
$\diamond$ if $\left(m_{b}^{1}, m_{b}^{2}\right)=\left(m_{b}^{1}\left(v_{b}\right), N K\right),\left(m_{s}^{1}, m_{s}^{2}\right)$ is a message used in equilibrium by some type of the seller and

* if $m_{s}^{1}>m_{b}^{1}$, then bid 0 .

* if $m_{s}^{1} \leq m_{b}^{1}$ and $m_{s}^{2}=K$, then bid $m_{s}^{1}$.

* if $m_{s}^{1} \leq m_{b}^{1}$ and $m_{s}^{2}=N K$, then bid $\frac{1}{2}\left(m_{b}^{1}+m_{s}^{1}\right)$.

$\diamond$ if for any player $i$, the message $\left(m_{i}^{1}, m_{i}^{2}\right)$ is not used in equilibrium by any type of player $i$, then bid 0.

3. For the behavioral-type seller of valuation $v_{s}$ :

(a) In the communication stage, announce $m_{s}^{1}=v_{s}$ and $m_{s}^{2}=K$.

(b) In the double-auction stage,

$\diamond$ if $\left(m_{s}^{1}, m_{s}^{2}\right)=\left(v_{s}, K\right),\left(m_{b}^{1}, m_{b}^{2}\right)$ is a message used in equilibrium by some type of the buyer and

* if $m_{s}^{1}>m_{b}^{1}$, then bid 1 .

* if $m_{s}^{1} \leq m_{b}^{1}$ and $m_{b}^{2}=K$, then bid $\frac{1}{2}\left(m_{b}^{1}+m_{s}^{1}\right)$.

* if $m_{s}^{1} \leq m_{b}^{1}$ and $m_{b}^{2}=N K$, then bid $m_{s}^{1}$.

$\diamond$ if for any player $i$, the message $\left(m_{i}^{1}, m_{i}^{2}\right)$ is not used in equilibrium by any type of player $i$, then bid 1 .

4. For the strategic-type seller of valuation $v_{s}$ :

(a) In the communication stage, announce $m_{s}^{2}=N K$ and

$$
m_{s}^{1}\left(v_{s}\right) \equiv\left\{\begin{array}{cl}
\alpha(\epsilon) v_{s}+\gamma(\epsilon) & \text { if } v_{s} \leq \alpha(\epsilon)+\beta(\epsilon) \\
v_{s} & \text { if } v_{s}>\alpha(\epsilon)+\beta(\epsilon)
\end{array}\right.
$$

(b) In the double-auction stage,

$\diamond$ if $\left(m_{s}^{1}, m_{s}^{2}\right)=\left(m_{s}^{1}\left(v_{s}\right), N K\right),\left(m_{b}^{1}, m_{b}^{2}\right)$ is a message used in equilibrium by some type of the buyer and

* if $m_{s}^{1}>m_{b}^{1}$, then bid 1 .

* if $m_{s}^{1} \leq m_{b}^{1}$ and $m_{b}^{2}=K$, then bid $m_{b}^{1}$.

* if $m_{s}^{1} \leq m_{b}^{1}$ and $m_{b}^{2}=N K$, then bid $\frac{1}{2}\left(m_{b}^{1}+m_{s}^{1}\right)$.

$\diamond$ if for any player $i$, the message $\left(m_{i}^{1}, m_{i}^{2}\right)$ is not used in equilibrium by any type of player $i$, then bid 1 . 
- Beliefs: In any continuation game $\left[\left(m_{b}^{1}, m_{b}^{2}\right),\left(m_{s}^{1}, m_{s}^{2}\right)\right]$ such that the message $\left(m_{i}^{1}, m_{i}^{2}\right)$ is used in equilibrium by some type $\left(v_{i}, d_{i}\right)$ of player $i$ in the communication stage, the belief of player $j$ is that player $i$ is of type $\left(v_{i}, d_{i}\right)$.

Thus, in equilibrium, unlike the behavioral types, all strategic types announce that they are not keen to trade and some strategic types shade or exaggerate their announced valuations relative to their true valuations. In particular, a strategic-type buyer of valuation $v_{b}$ announces her valuation as $m_{b}^{1}\left(v_{b}\right)=\min \left\{v_{b}, \alpha(\epsilon) v_{b}+\beta(\epsilon)\right\}$. Note that $m_{b}^{1}\left(v_{b}\right)$ is a piecewise-linear and continuous function that takes the value $v_{b}$ whenever $v_{b} \leq \gamma(\epsilon)$ and the value $\alpha(\epsilon) v_{b}+\beta(\epsilon)<v_{b}$ whenever $v_{b}>\gamma(\epsilon)$ (see Lemma 2). Thus, low valuation types of the strategic-type buyer-those with $v_{b} \leq \gamma(\epsilon)$-truthfully reveal their valuations while high valuation types of the strategic-type buyer - those with $v_{b}>\gamma(\epsilon)$-shade their announced valuations to $\alpha(\epsilon) v_{b}+\beta(\epsilon)<v_{b}$ (see Figure 1). Similarly, a strategic-type seller of valuation $v_{s}$ announces her valuation as $m_{s}^{1}\left(v_{s}\right)=\max \left\{v_{s}, \alpha(\epsilon) v_{s}+\gamma(\epsilon)\right\} \cdot m_{s}^{1}\left(v_{s}\right)$ is also a piecewise-linear and continuous function and it takes the value $\alpha(\epsilon) v_{s}+\gamma(\epsilon)>v_{s}$ whenever $v_{s}<\alpha(\epsilon)+\beta(\epsilon)$ and the value $v_{s}$ whenever $v_{s} \geq \alpha(\epsilon) v_{s}+\gamma(\epsilon)$ (see Lemma 3). Thus, high valuation types of the strategic-type seller-those with $v_{s} \geq \alpha(\epsilon)+\beta(\epsilon)$ - truthfully reveal their valuations while low valuation types of the strategic-type seller-those with $v_{s}<\alpha(\epsilon)+\beta(\epsilon)$ - exaggerate their announced valuations to $\alpha(\epsilon) v_{s}+\gamma(\epsilon)>v_{s}$ (see Figure $1)$.

In the double-auction stage, all types of the players walk away from trade by bidding the extreme values of 0 or 1 if the announced valuations suggest that there can be no gains from trade, that is, $m_{s}^{1}>m_{b}^{1}$. Whereas if the announced valuations are such that $m_{s}^{1} \leq m_{b}^{1}$, then a strategic-type of player $i$ coordinates on the price of $m_{j}^{1}$ if player $j$ is keen to trade while she coordinates on the price of $\frac{1}{2}\left(m_{b}^{1}+m_{s}^{1}\right)$ if player $j$ is not keen to trade. On the other hand, if the announced valuations are such that $m_{s}^{1} \leq m_{b}^{1}$, then a behavioral-type of player $i$ coordinates on the price of $\frac{1}{2}\left(m_{b}^{1}+m_{s}^{1}\right)$ if player $j$ is keen to trade while she coordinates on the price of $m_{i}^{1}$ if player $j$ is not keen to trade. Simply put, the players coordinate on either a single-price or no-trade equilibrium in the double-auction stage continuation games. However, in coordinating on a single-price equilibrium, different dispositions types adopt different bargaining positions in the double auction. Strategic types take a "tougher" position conceding no gains from trade suggested by the announced valuations if the other player is keen to trade and at most half the gains from trade suggested by the announced valuations if the other player is also not keen to trade. As a response, behavioral types accept a "weaker" position conceding all the gains from trade suggested by the announced 
valuations if the other player is not keen to trade and at most half the gains from trade suggested by the announced valuations if the other player announces that she is also keen to trade.

The reason why some strategic types reveal their valuations truthfully is because their announced valuations do not impact the price at which they trade in the double auction. For instance, consider the strategic-type buyer of valuation $v_{b} \leq \gamma(\epsilon)$. In the double auction, it is not optimal for her to trade with those types of the seller whose announced valuations are greater than $v_{b}$ since such types of the seller always bid at least $v_{b}$. Thus, our strategic-type buyer would not want to announce any valuation greater than her true valuation. However, the only types of the seller whose announced valuations are at most $v_{b} \leq \gamma(\epsilon)$ are the behavioral types of the seller of valuations $v_{s} \leq v_{b}$. These behavioral types of the seller bid equal to their true valuations $v_{s}$ in the double auction if the buyer announces that she is not keen to trade and $m_{b}^{1} \geq m_{s}^{1}=v_{s}$. Thus, if our strategic buyer were to shade her announced valuation, then she would loose the opportunity to trade with some behavioral types of the seller without impacting the price of any gainful trade.

On the other hand, the reason why some strategic types shade/exaggerate their announced valuations relative to their true valuations is because their announced valuations impact the price at which they trade in the double auction. For instance, consider the strategic-type buyer of valuation $v_{b}>\gamma(\epsilon)$. Again, this strategic-type buyer would not want to announce any valuation greater than her true valuation; it is not optimal for her to trade with those types of the seller whose announced valuations are greater than $v_{b}$ since such types of the seller always bid at least $v_{b}$. But now there are both behavioral and strategic types of the seller whose announced valuations are at most $v_{b}$. The valuation announced by our strategic-type buyer only determines the probability she trades with a behavioral type of the seller since such a seller bids equal to her true valuation $v_{s}$ in the double auction if the buyer announces that she is not keen to trade and $m_{b}^{1} \geq m_{s}^{1}=v_{s}$. However, the valuation announced by our strategic-type buyer not only determines the probability she trades with a strategic type of the seller but also the price of such a trade since such a seller bids equal to $\frac{1}{2}\left(m_{b}^{1}+m_{s}^{1}\right)$ in the double auction if the buyer announces that she is not keen to trade and $m_{b}^{1} \geq m_{s}^{1}$. Thus, a strategic-type buyer of valuation $v_{b}>\gamma(\epsilon)$ faces a trade-off between a higher probability of trade if she were to announce a higher valuation versus a lower price if she were to announce a lower valuation. Thus, it is optimal for her to shade her announced valuation; after all, trading with a seller who bids close to $v_{b}$ generates very little profit but increases the price on a large fraction of trades. It is also not optimal for any strategic type 
to imitate another behavioral type by announcing that she is keen to trade. Consider the two announcements $\left(m_{b}^{1}, K\right)$ and $\left(m_{b}^{1}, N K\right)$ (the proof takes care of all cases). If a strategictype buyer were to announce $\left(m_{b}^{1}, K\right)$ instead of $\left(m_{b}^{1}, N K\right)$, then this does not change the probability that she trades with any seller since the announced valuations are the same in both announcements. However, announcing that she is keen to trade instead of not keen to trade indicates to the seller that she is a behavioral type who will take a "weaker" bargaining position in the double auction. This induces all types of the seller to bid higher and thus demand a higher share of the gains from trade suggested by the announced valuations, which is obviously not in the buyer's interest.

\subsection{Comparative statics with respect to $\epsilon$}

Before we discuss how a change in $\epsilon$ impacts the equilibrium outcome, we note the following properties of $\alpha(\epsilon), \beta(\epsilon)$ and $\gamma(\epsilon)$ (proof is available upon request):

Lemma 1. Properties of $\alpha(\epsilon), \beta(\epsilon)$ and $\gamma(\epsilon)$.

1. $\alpha^{\prime}(\epsilon)>0, \lim _{\epsilon \rightarrow 0} \alpha(\epsilon)=\frac{2}{3}$ and $\lim _{\epsilon \rightarrow 1} \alpha(\epsilon)=1$.

2. $\beta^{\prime}(\epsilon)<0, \lim _{\epsilon \rightarrow 0} \beta(\epsilon)=\frac{1}{12}$ and $\lim _{\epsilon \rightarrow 1} \beta(\epsilon)=0$.

3. $\gamma^{\prime}(\epsilon)<0, \lim _{\epsilon \rightarrow 0} \gamma(\epsilon)=\frac{1}{4}$ and $\lim _{\epsilon \rightarrow 0} \gamma(\epsilon)=0$.

Since $\alpha(\epsilon), \beta(\epsilon)$ and $\gamma(\epsilon)$ determine the valuations announced by the strategic types in the communication stage, a change in $\epsilon$ changes these announcements. Figure 1 shows how by comparing the valuations announced by the strategic types when $\epsilon=0.01$ and $\epsilon=0.5$. As the figure shows, an increase in $\epsilon$ induces some strategic types to shade/exaggerate lessmathematically, this is due to $\alpha^{\prime}(\epsilon)>0$ - while some strategic types shade/exaggerate more due to an increase in $\epsilon$-mathematically, this is due to $\beta^{\prime}(\epsilon), \gamma^{\prime}(\epsilon)<0$. Intuitively, an increase in $\epsilon$ means that the other player is more likely to be behavioral type who announces her valuation truthfully in the communication stage. Then any level of shading/exaggeration in the communication stage becomes more costly since the player is more likely to loose the opportunity to trade as the behavioral types walk away from trade if the other players' announced valuation suggest that there do not exist any gains from trade. This explains why high-valuation types of the strategic-type buyer shade less and low-valuation types of the strategic-type seller exaggerate less in the communication stage when $\epsilon$ increases. This 


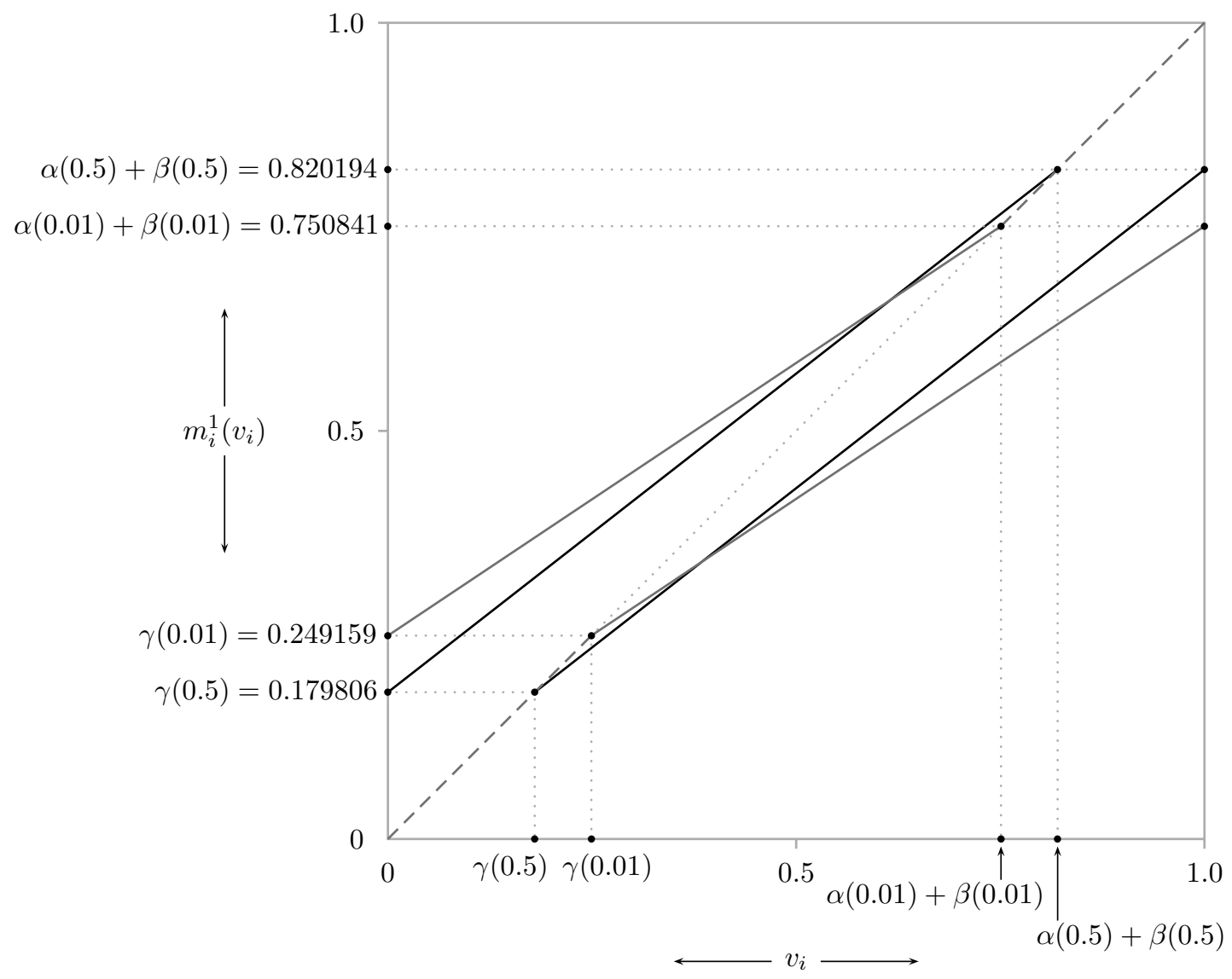

Figure 1: Valuations announced by the strategic types in the communication stage: Lines below (above) the diagonal are for the buyer (seller). When $\epsilon=0.01$, all valuation types of the strategictype buyer with $v_{b}>\gamma(0.01)$ shade and all valuation types of the strategic-type seller with $v_{s}<$ $\alpha(0.01)+\beta(0.01)$ exaggerate their announced valuations (solid-gray lines); whereas all valuation types of the strategic-type buyer with $v_{b} \leq \gamma(0.01)$ and all valuation types of the strategic-type seller with $v_{s} \geq \alpha(0.01)+\beta(0.01)$ truthfully reveal their valuations (dashed-gray lines). On the other hand, when $\epsilon=0.5$, all valuation types of the strategic-type buyer with $v_{b}>\gamma(0.5)$ shade and all valuation types of the strategic-type seller with $v_{s}<\alpha(0.5)+\beta(0.5)$ exaggerate their announced valuations (solid-black lines); whereas all valuation types of the strategic-type buyer with $v_{b} \leq \gamma(0.5)$ and all valuation types of the strategic-type seller with $v_{s} \geq \alpha(0.5)+\beta(0.5)$ truthfully reveal their valuations (dashed-gray lines).

in turn induces the low-valuation types of the strategic-type buyer to shade more and highvaluation types of the strategic-type seller to exaggerate more in the communication stage. For instance, less exaggeration by the low-valuation types of the strategic-type seller when $\epsilon$ increases implies that for a low-valuation type of the strategic-type buyer, the probability that the seller announces a valuation less than her valuation increases. Therefore, such a strategic-type buyer prefers to take advantage of this by reducing her announced valuation 
and thereby reducing the price at which she trades with the strategic types of the sellers in the double-auction stage.

Using Lemma 1, we note that $\lim _{\epsilon \rightarrow 1}\left[\alpha(\epsilon) v_{b}+\beta(\epsilon)\right]=v_{b}$ and $\lim _{\epsilon \rightarrow 1}\left[\alpha(\epsilon) v_{s}+\gamma(\epsilon)\right]=v_{s}$. Therefore, as $\epsilon$ converges to 1 , all strategic types of the players truthfully announce their respective valuations in the communication stage. On the other hand, $\lim _{\epsilon \rightarrow 0}\left[\alpha(\epsilon) v_{b}+\beta(\epsilon)\right]=$ $\frac{2}{3} v_{b}+\frac{1}{12}$ and $\lim _{\epsilon \rightarrow 0}\left[\alpha(\epsilon) v_{s}+\gamma(\epsilon)\right]=\frac{2}{3} v_{s}+\frac{1}{4}$. The reader will recall that the CS equilibrium is such that the buyer bids $\min \left\{v_{b}, \frac{2}{3} v_{b}+\frac{1}{12}\right\}$ while the seller bids $\max \left\{v_{s}, \frac{2}{3} v_{s}+\frac{1}{4}\right\}$. Thus, as $\epsilon$ converges to 0 , the valuations announced by the strategic types of the players in the communication stage converge to the respective CS equilibrium bids.

\section{Comparison with CS equilibrium}

An allocation rule is a pair of functions $(p, x)$ such that for any pair of types of the two players $\left(v_{b}, d_{b}\right)$ and $\left(v_{s}, d_{s}\right), p\left[\left(v_{b}, d_{b}\right),\left(v_{s}, d_{s}\right)\right] \in[0,1]$ is the probability that the object is traded and $x\left[\left(v_{b}, d_{b}\right),\left(v_{s}, d_{s}\right)\right] \in \Re$ is the payment from the buyer to the seller. It is straightforward to check that the allocation rule obtained in the equilibrium specified in Proposition 1 is such that (in specifying $p\left[\left(v_{b}, s t\right),\left(v_{s}, s t\right)\right]$, we use the fact that $\gamma(\epsilon)=\frac{\gamma(\epsilon)-\beta(\epsilon)}{\alpha(\epsilon)}$; see proof of Lemma 2):

$$
\begin{aligned}
& p\left[\left(v_{b}, s t\right),\left(v_{s}, s t\right)\right]= \begin{cases}1 & \text { if } v_{b} \geq v_{s}+\gamma(\epsilon) \\
0 & \text { if } v_{b}<v_{s}+\gamma(\epsilon)\end{cases} \\
& p\left[\left(v_{b}, s t\right),\left(v_{s}, b h\right)\right]= \begin{cases}1 & \text { if } \min \left\{v_{b}, \alpha(\epsilon) v_{b}+\beta(\epsilon)\right\} \geq v_{s} \\
0 & \text { if } \min \left\{v_{b}, \alpha(\epsilon) v_{b}+\beta(\epsilon)\right\}<v_{s}\end{cases} \\
& p\left[\left(v_{b}, b h\right),\left(v_{s}, s t\right)\right]= \begin{cases}1 & \text { if } v_{b} \geq \max \left\{v_{s}, \alpha(\epsilon) v_{s}+\gamma(\epsilon)\right\} \\
0 & \text { if } v_{b}<\max \left\{v_{s}, \alpha(\epsilon) v_{s}+\gamma(\epsilon)\right\}\end{cases} \\
& p\left[\left(v_{b}, b h\right),\left(v_{s}, b h\right)\right]= \begin{cases}1 & \text { if } v_{b} \geq v_{s} \\
0 & \text { if } v_{b}<v_{s}\end{cases}
\end{aligned}
$$

In the CS equilibrium, the allocation rule is a function only of the pair of valuations since both players are only strategic type. The allocation rule obtained in the CS equilibrium is such that the probability of trade is as follows:

$$
p^{C S}\left(v_{b}, v_{s}\right)= \begin{cases}1 & \text { if } v_{b} \geq v_{s}+\frac{1}{4} \\ 0 & \text { if } v_{b}<v_{s}+\frac{1}{4}\end{cases}
$$


The following corollary is our main result.

Corollary 1. The following hold for any $\epsilon \in(0,1)$.

1. For any ex-post realization of types $\left[\left(v_{b}, d_{b}\right),\left(v_{s}, d_{s}\right)\right]$, the allocation rule obtained in our equilibrium is such that $p\left[\left(v_{b}, d_{b}\right),\left(v_{s}, d_{s}\right)\right] \geq p^{C S}\left(v_{b}, v_{s}\right)$.

2. For any ex-post realization of disposition types $\left(d_{b}, d_{s}\right)$, there exists a set of positive measure $V \subset[0,1] \times[0,1]$ such that for all $\left(v_{b}, v_{s}\right) \in V$, the allocation rule obtained in our equilibrium has $p\left[\left(v_{b}, d_{b}\right),\left(v_{s}, d_{s}\right)\right]=1>0=p^{C S}\left(v_{b}, v_{s}\right)$.

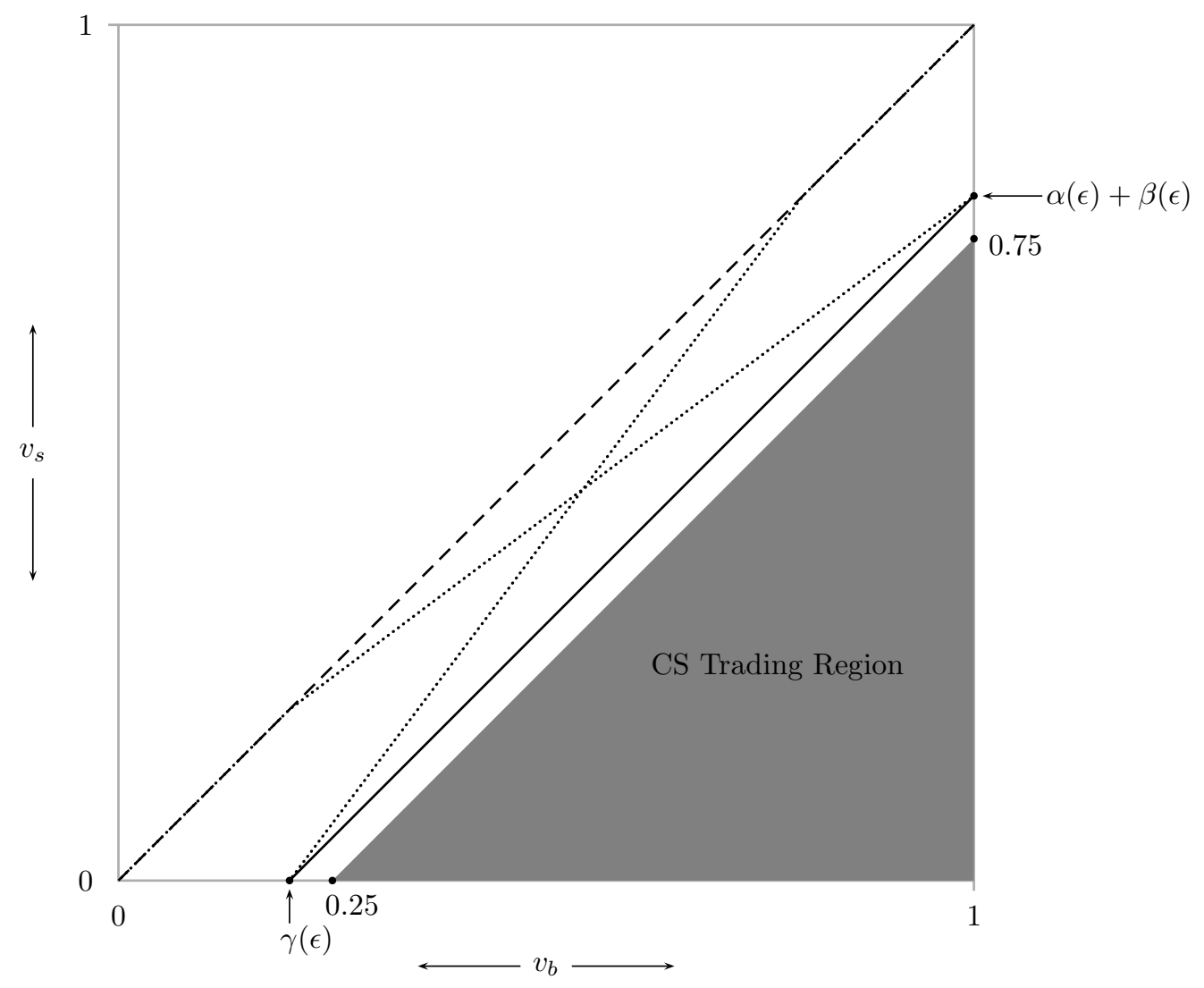

Figure 2: Trading Regions: The region below the dashed-black line is where trade is desirable. This is also the trading region in the event both players are behavioral type. The region below the solid-black line is the trading region in the event both players are strategic type. The region below the dotted-black line that kinks at $[\gamma(\epsilon), \gamma(\epsilon)]$ is the trading region in the event the buyer is strategic and the seller is behavior type. The region below the dotted-black line that kinks at $[\alpha(\epsilon)+\beta(\epsilon), \alpha(\epsilon)+\beta(\epsilon)]$ is the trading region in the event the buyer is behavioral and the seller is strategic type. The solid gray region is the trading region in the CS equilibrium.

Thus, if a pair of valuation types $\left(v_{b}, v_{s}\right)$ trades in the CS equilibrium, then that pair of valuation types also trades in our equilibrium irrespective of the corresponding disposition 
types of the players. Figure 2 graphically conveys the meaning of the above corollary. For any $\epsilon \in(0,1)$ and for any realization of the disposition types of the two players, the set of valuations types who trade in our equilibrium is larger that the set of valuations types who trade in the CS equilibrium.

Therefore, for any $\epsilon \in(0,1)$, the ex-ante probability of trade conditional on any realization of the disposition types of the two players is higher in our equilibrium compared to the CS equilibrium. This further implies that for any $\epsilon \in(0,1)$, the total ex-ante probability of trade in higher in our equilibrium than in the CS equilibrium. Figure 3 shows the total ex-ante probability of trade and ex-ante probabilities of trade conditional on different realization of disposition types as functions of $\epsilon$. Recall that the valuations announced by the strategic-type players converge to the CS equilibrium bids as $\epsilon$ converges to 0 . That is why, as shown in the figure, the total ex-ante probability of trade and the ex-ante probability of trade conditional on both players being strategic type converge to 0.28125 (the ex-ante probability of trade in the CS equilibrium) as $\epsilon$ converges to 0 . On the other hand, as $\epsilon$ converges to 1 , all strategic types truthfully announce their respective valuations in the communication stage. Therefore, the total ex-ante probability of trade and the ex-ante probability of trade conditional on any realization of disposition types converge to 0.5 as $\epsilon$ converges to 1.

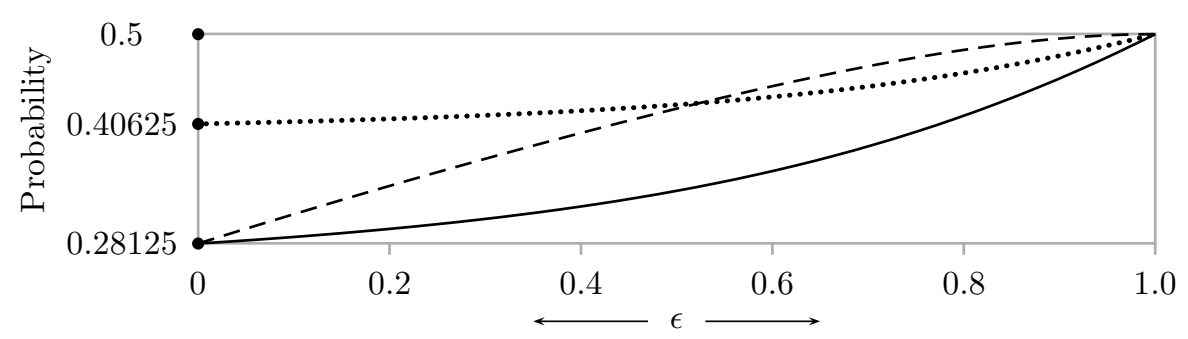

Figure 3: Ex-ante probability of trade for different values of $\epsilon$ : Dashed-black line shows the total ex-ante probability of trade. Dotted-black line shows the ex-ante probability of trade in the event that one player is strategic and the other player is behavioral type. Solid-black line shows the exante probability of trade in the event that both players are strategic type. The ex-ante probability of trade in the event that both players are behavioral type is 0.5 for all $\epsilon$. 0.28125 is the ex-ante probability of trade in the CS equilibrium.

In our equilibrium, any pair of types $\left[\left(v_{b}, d_{b}\right),\left(v_{s}, d_{s}\right)\right]$ trade with a positive probability only if $v_{b} \geq v_{s}$. Therefore, Corollary 1 also implies that our equilibrium generates at least as much ex-post gains from trade as the CS equilibrium and irrespective of the realization of the disposition types, there exists a positive measure of valuations types who obtain strictly higher ex-post gains from trade in our equilibrium compared to the CS equilibrium. Thus, 


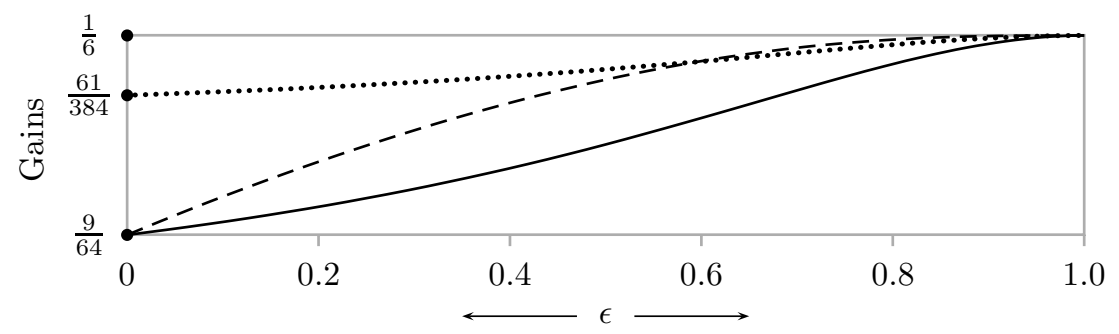

Figure 4: Ex-ante gains from trade for different values of $\epsilon$ : Dashed-black line shows the total ex-ante gains from trade. Dotted-black line shows the ex-ante gains from trade in the event that one player is strategic and the other player is behavioral type. Solid-black line shows the ex-ante gains from trade in the event that both players are strategic type. The ex-ante gains from trade in the event that both players are behavioral type are 1/6 (the highest possible value) for all $\epsilon$. The ex-ante gains from trade in the CS equilibrium are $9 / 64$.

the allocation rule obtained in our equilibrium dominates the CS equilibrium in terms of ex-post gains from trade. This of course implies that players obtain higher ex-ante gains from trade conditional on any realization of disposition types and hence higher total ex-ante gains from trade than in the CS equilibrium. Figure 4 shows the total ex-ante gains from trade and ex-ante gains from trade conditional on different realization of disposition types as functions of $\epsilon$. Again, as $\epsilon$ converges to 0, the announced valuations converge to the CS equilibrium bids and therefore, the total ex-ante gains from trade and the ex-ante gains from trade conditional on both players being strategic type converge to $\frac{9}{64}$ (the ex-ante gains from trade in CS equilibrium). While, as $\epsilon$ converges to 1, strategic types announce their valuations truthfully; so the total ex-ante gains from trade and the ex-ante gains from trade conditional on any realization of disposition types converge to the highest possible value of $\frac{1}{6}$.

\section{Discussion}

Is preplay communication necessary? The allocation rule obtained in our equilibrium cannot be obtained without preplay communication. To see this, consider the strategic-type buyer of valuation $v_{b}$. Pick a $v_{s}$ such that $m_{s}^{1}\left(v_{s}\right) \leq m_{b}^{1}\left(v_{b}\right)$. If the seller is a strategic-type of valuation $v_{s}$, then the price paid by the strategic-type buyer is $\frac{1}{2}\left[m_{b}^{1}\left(v_{b}\right)+m_{s}^{1}\left(v_{s}\right)\right]$, which increase as $v_{b}$ increase, whereas if the seller is a behavioral-type of valuation $v_{s}$, then the price paid by the strategic-type buyer is $v_{s}$, which does not depend on $v_{b}$. This cannot happen in a double auction; if the price paid by a buyer to a type of the seller with whom she trades changes as her valuation changes then so must the price paid by her to another type of the 
seller with whom she trades.

A related question is does there exist some other allocation rule that can be obtained in equilibrium without preplay communication but has strictly higher ex-ante gains from trade or ex-ante probability of trade than the CS equilibrium? The answer is no, given our weak assumption about the behavioral types. We have only assumed that the behavioral types communicate nonstrategically. In the double auction, behavioral types act strategically. Thus, without preplay communication, all types will act strategically and hence, any equilibrium allocation rule will be subject to the upper bound on efficiency that is obtained in the CS equilibrium. This is in line with the experiments that do not observe any significant improvement in efficiency over the CS equilibrium when the players are not allowed to communicate before bidding in the double auction (Radner and Schotter (1989), Valley et al. (2002), McGinn et al. (2003)). Of course, it might be possible that if we make some other assumption about the behavioral types in the double auction without preplay communication, then we do obtain an equilibrium allocation rule that beats the CS-equilibrium upper bound on efficiency. However, in our opinion, the experimental evidence does not offer any basis for such an assumption.

\section{Is it necessary that the players have the option to announce messages other than}

their valuations? We assumed that in the communication stage, the players have the option to announce not only their respective valuations but also whether they are keen or not keen to trade. If players differ not only in terms of their valuations but also in terms of their strategic or behavioral disposition, then the type of a player is a pair $\left(v_{i}, d_{i}\right)$. Moreover, the behavioral types truthfully announce their respective valuations in the communication stage. Therefore, in order to construct a fully separating equilibrium, we need that the message space for any player in the communication stage is richer than the set of valuations.

Furthermore, some separation between the two disposition types in the communication stage is necessary for an improvement in efficiency. For instance, consider the set of equilibria in which there is no separation between the disposition types during the communication stage; thus, each strategic type of valuation $v_{i}$ also announces $\left(v_{i}, K\right) .{ }^{10}$ Even though these equilibria have a complete separation between the valuation types, it can be shown that no such equilibrium has a higher ex-ante gains from trade or ex-ante probability of trade than the CS equilibrium. ${ }^{11}$ Thus, some separation between the disposition types is necessary to

\footnotetext{
${ }^{10}$ The set of such equilibria is nonempty; in fact, any equilibrium outcome of the $\frac{1}{2}$-double auction without preplay communication can be obtained in some such equilibrium.

${ }^{11}$ Since the disposition types do not separate in the communication stage and the behavioral types bid
} 
provide adequate incentives to the strategic-type players to reduce the misrepresentation of their private information that causes inefficiencies. Such incentives are present in our fully separating equilibrium - however, full separation is not always sufficient for the result. ${ }^{12}$ By announcing that they are not keen to trade, the strategic types make known their "tougher" bargaining position, which separates them from the behavioral types who are left to accept a "weaker" bargaining position because of their inability to deviate in the communication stage. This in turn reduces the shading/exaggeration in the announcement of their valuations by the strategic types; otherwise, they are more likely to miss the opportunity to trade with the "weaker" behavioral types.

In the real world or in experiments with unfettered preplay communication, bargainers indeed have access to a rich message space. In such instances, bargainers do not restrict themselves to announcing only their valuations. Valley et al. (2002, p. 148) quote a seller in their experiment who sent the following message to the buyer, "Let's get down to business. We are here to earn money, right? So, we'll have to negotiate. Let's be straight and honest. My cost is $\$ 19$." This seller is clearly suggesting more than just that her cost is $\$ 19$; she also wants the buyer to believe that she is "straight and honest". And even if the players cannot send such explicit verbal or written messages, simple cues like smiles, winks and handshakes are always available whenever players are face-to-face. As Manzini et al. (2009) show in their experiment on the minimum effort game, such simple cues have significant informational value and are used by players as coordination devices.

\section{Is it necessary that the behavioral types announce "keen to trade"? No, all} the results can be obtained if were to instead assume that a behavioral-type player only truthfully reveals her valuation in preplay communication. However, we will have to change the preplay message space accordingly. Suppose that in the communication stage each player must simultaneously announce her valuation twice - again, since type is a pair, we need a message space that is richer than the set of valuations. But in announcing her valuation, a player can choose any real number. Thus, the set of messages available to each player $i$ is $\left(m_{i}^{1}, m_{i}^{2}\right) \in \Re^{2}$. After this communication stage, the players play the $\frac{1}{2}$-double auction. Being truthful, any behavioral-type player of valuation $v_{i}$ sends the message $\left(v_{i}, v_{i}\right)$. There exists an equilibrium of this game which attains the same allocation rule as the equilibrium

strategically, the allocation rule obtained in such an equilibrium is incentive compatible (no type of a player can gain by imitating another type of the player) and individually rational (each type gets a nonnegative expected payoff). The result follows using Myerson and Satterthwaite (1983).

${ }^{12}$ For instance, there exists a fully separating equilibrium in which after any pair of announcements, the players play the no-trade equilibrium. 
in Proposition 1. In this equilibrium, the strategic-type player of valuation $v_{i}$ sends the same first message $m_{i}^{1}=m_{i}^{1}\left(v_{i}\right)$ as in Proposition 1 but for the second message she chooses a number $m_{i}^{2}\left(v_{i}\right) \notin[0,1]$. By sending $m_{i}^{2}\left(v_{i}\right) \notin[0,1]$, this strategic type separates herself from any behavioral type. In any continuation game with $m_{j}^{1}=m_{j}^{2}=v_{j} \in[0,1]$, each type of player $i$ plays the same strategy as in the continuation game following a $\left(v_{j}, K\right)$ announcement in the equilibrium in Proposition 1; whereas in any continuation game with $m_{j}^{1}=m_{j}^{1}\left(v_{j}\right)$ and $m_{j}^{2}=m_{j}^{2}\left(v_{j}\right)$ for some $v_{j} \in[0,1]$, each type of player $i$ plays the same strategy as in the continuation game following a $\left(m_{j}^{1}, N K\right)$ announcement in the equilibrium in Proposition 1. In all other continuations games, the players play the no-trade equilibrium. Thus, like in the equilibrium in Proposition 1, the strategic-type players are able to signal their valuations using the first message and their intention to adopt a "tougher" bargaining position in the double auction using the second message.

\section{Conclusion}

We proved that, like in the experiments on bargaining with preplay communication, it is also theoretically feasible to obtain a higher efficiency that the CS equilibrium if we adjust the theoretical models in light of evidence from these very experiments, which suggests that a proportion of the population nonstrategically reveals their private information during preplay communication. Our theoretical analysis not only confirms the experimental finding that honest revelation and coordination on single-price equilibira using preplay communication enhances efficiency but also provides a novel explanation: the strategic response of using preplay communication to signal their "tougher" bargaining intentions against the honest players that in turn induces the strategic types to reduce the misrepresentation of their private information.

Nevertheless, the equilibrium in Proposition 1 is not the unique equilibrium of the game (see Section 4). There are many equilibria that have lower total ex-ante gains from trade or ex-ante probability of trade than the CS equilibrium. This raises the following question: what guarantees that the players coordinate on the equilibrium in Proposition 1 that improves efficiency? Although this is an important question, it is beyond the scope of this paper and is left for future research. 


\section{Proofs}

Lemma 2. $v_{b} \gtreqless \alpha(\epsilon) v_{b}+\beta(\epsilon) \Longleftrightarrow v_{b} \gtreqless \gamma(\epsilon)$.

Proof. Let $f\left(v_{b}\right)=v_{b}$ and $g\left(v_{b}\right)=\alpha(\epsilon) v_{b}+\beta(\epsilon)$. Now, $f^{\prime}\left(v_{b}\right)=1$ and $g^{\prime}\left(v_{b}\right)=\alpha(\epsilon) \epsilon$ $\left(\frac{2}{3}, 1\right)$ (follows from Lemma 1 ). Therefore, to prove the lemma, it is sufficient to show that $\alpha(\epsilon) \gamma(\epsilon)+\beta(\epsilon)=\gamma(\epsilon)$.

$$
\begin{aligned}
& \beta(\epsilon)+\gamma(\epsilon)[\alpha(\epsilon)-1] \\
= & \gamma(\epsilon)\left(\frac{1-\epsilon}{3(1-\epsilon)+2 \epsilon \alpha(\epsilon)}-[1-\alpha(\epsilon)]\right) \\
= & \frac{\gamma(\epsilon)}{3(1-\epsilon)+2 \epsilon \alpha(\epsilon)}\{1-\epsilon-[1-\alpha(\epsilon)][3(1-\epsilon)+2 \epsilon \alpha(\epsilon)]\} \\
= & \frac{\gamma(\epsilon)}{3(1-\epsilon)+2 \epsilon \alpha(\epsilon)}\left\{2 \epsilon[\alpha(\epsilon)]^{2}-(5 \epsilon-3) \alpha(\epsilon)-2(1-\epsilon)\right\} \\
= & 0,
\end{aligned}
$$

where the last equality follows from the fact that $\alpha(\epsilon)=\frac{5 \epsilon-3+\sqrt{(5 \epsilon-3)^{2}+16 \epsilon(1-\epsilon)}}{4 \epsilon}$ is a root of the quadratic equation $2 \epsilon[\alpha(\epsilon)]^{2}-(5 \epsilon-3) \alpha(\epsilon)-2(1-\epsilon)=0$.

Lemma 3. $v_{s} \gtreqless \alpha(\epsilon) v_{s}+\gamma(\epsilon) \Longleftrightarrow v_{s} \gtreqless \alpha(\epsilon)+\beta(\epsilon)$.

Proof. Let $\hat{f}\left(v_{s}\right)=v_{s}$ and $\hat{g}\left(v_{s}\right)=\alpha(\epsilon) v_{s}+\gamma(\epsilon)$. Now, $\hat{f}^{\prime}\left(v_{s}\right)=1$ and $\hat{g}^{\prime}\left(v_{s}\right)=\alpha(\epsilon) \epsilon$ $\left(\frac{2}{3}, 1\right)$ (follows from Lemma 1). Therefore, to prove the lemma, it is sufficient to show that $\alpha(\epsilon)[\alpha(\epsilon)+\beta(\epsilon)]+\gamma(\epsilon)=\alpha(\epsilon)+\beta(\epsilon)$.

$$
\begin{aligned}
& \alpha(\epsilon)[\alpha(\epsilon)+\beta(\epsilon)]+\gamma(\epsilon)-\alpha(\epsilon)-\beta(\epsilon) \\
= & \gamma(\epsilon)-\alpha(\epsilon)[1-\alpha(\epsilon)]-\beta(\epsilon)[1-\alpha(\epsilon)] \\
= & \gamma(\epsilon)-\alpha(\epsilon)[1-\alpha(\epsilon)]-\gamma(\epsilon)[1-\alpha(\epsilon)]^{2} \\
= & \alpha(\epsilon)\{\gamma(\epsilon)[2-\alpha(\epsilon)]-[1-\alpha(\epsilon)]\} \\
= & \frac{\alpha(\epsilon)}{4(1-\epsilon)+2 \epsilon \alpha(\epsilon)}\{[1-\epsilon][2-\alpha(\epsilon)]-[1-\alpha(\epsilon)][4(1-\epsilon)+2 \epsilon \alpha(\epsilon)]\} \\
= & \frac{\alpha(\epsilon)}{4(1-\epsilon)+2 \epsilon \alpha(\epsilon)}\left\{2 \epsilon[\alpha(\epsilon)]^{2}-(5 \epsilon-3) \alpha(\epsilon)-2(1-\epsilon)\right\} \\
= & 0,
\end{aligned}
$$

where the third equality uses the fact that $\beta(\epsilon)=\gamma(\epsilon)[1-\alpha(\epsilon)]$ (see proof of Lemma 2) 
and the last equality follows from the fact that $\alpha(\epsilon)=\frac{5 \epsilon-3+\sqrt{(5 \epsilon-3)^{2}+16 \epsilon(1-\epsilon)}}{4 \epsilon}$ is a root of the quadratic equation $2 \epsilon[\alpha(\epsilon)]^{2}-(5 \epsilon-3) \alpha(\epsilon)-2(1-\epsilon)=0$.

Proof of Proposition 1: We provide the proof only for the buyer, a similar argument works for the seller.

We have a fully separating equilibrium. So, in any continuation game $\left[\left(m_{b}^{1}, m_{b}^{2}\right),\left(m_{s}^{1}, m_{s}^{2}\right)\right]$ such that the message $\left(m_{i}^{1}, m_{i}^{2}\right)$ is used in equilibrium by some type $\left(v_{i}, d_{i}\right)$ of player $i$ in the communication stage, the belief of player $j$ is that player $i$ is of type $\left(v_{i}, d_{i}\right)$. On the other hand, consider any off-the-equilibrium path continuation game $\left[\left(m_{b}^{1}, m_{b}^{2}\right),\left(m_{s}^{1}, m_{s}^{2}\right)\right]$ such that the message $\left(m_{i}^{1}, m_{i}^{2}\right)$ is not used in equilibrium by any type of player $i$ in the communication stage. The proof is such that we do not have to specify the belief of player $j$ about player $i$ in such a continuation game. The reason is that according to the strategies specified in the proposition, any type of any player $i$ bids an extreme value (0 if she is a buyer and 1 if she is a seller) such that player $j$ cannot gain a positive amount by trading with player $i$. Thus, in such a continuation game, irrespective of the belief of player $j$ about player $i$, it is a best response for any type of player $j$ to also bid an extreme value ( 1 if she is a seller and 0 if she is a buyer). Given this extreme bid by any type of player $j$, it is also a best response for any type of player $i$ to bid the extreme value. Thus, irrespective of the specific beliefs about each others types, the strategies of both the players to bid extreme values are mutual best responses in such a continuation game.

The proposition also does not specify the strategy of any type $\left(v_{i}, d_{i}\right)$ of any player $i$ in those continuation games $\left[\left(m_{b}^{1}, m_{b}^{2}\right),\left(m_{s}^{1}, m_{s}^{2}\right)\right]$ such that both messages $\left(m_{b}^{1}, m_{b}^{2}\right)$ and $\left(m_{s}^{1}, m_{s}^{2}\right)$ are used, respectively, by some type $\left(v_{b}^{\prime}, d_{b}^{\prime}\right)$ of the buyer and $\left(v_{s}^{\prime}, d_{s}^{\prime}\right)$ of the seller in equilibrium but $\left(m_{i}^{1}, m_{i}^{2}\right)$ is not an equilibrium message of type $\left(v_{i}, d_{i}\right)$ of player $i$. In such a continuation game, the belief of player $j$ is that player $i$ is of type $\left(v_{i}^{\prime}, d_{i}^{\prime}\right)$ and thus, player $j$ will play optimally against that belief. Therefore, what type $\left(v_{i}, d_{i}\right)$ of player $i$ does in such a continuation game does not affect the behavior of player $j$. The only requirement is that type $\left(v_{i}, d_{i}\right)$ must believe that player $j$ is of type $\left(v_{j}^{\prime}, d_{j}^{\prime}\right)$ and play optimally against that belief. However, instead of specifying the strategy of the strategic-type of player $i$ in such a continuation game, we argue that no strategic-type of player $i$ can increase her expected payoff by imitating another type of player $i$ in the communication stage and then playing optimally in any continuation game. We do not need to make such an argument for the behavioral-type of player $i$ since she cannot deviate in the communication stage. Therefore, if a behavioral type of player $i$ were to find herself in such a continuation game, then without being specific about her strategy, we only say that she plays optimally against her belief that 
player $j$ is of type $\left(v_{j}^{\prime}, d_{j}^{\prime}\right)$.

Case 1: Consider the behavioral-type buyer of valuation $v_{b}$. We only need to show that this behavioral-type buyer is playing optimally in the continuation games.

First, consider the continuation game $\left[\left(m_{b}^{1}, m_{b}^{2}\right),\left(m_{s}^{1}, m_{s}^{2}\right)\right]$ such that $\left(m_{b}^{1}, m_{b}^{2}\right)=\left(v_{b}, K\right)$ and $\left(m_{s}^{1}, m_{s}^{2}\right)$ is a message used in equilibrium by some type $\left(v_{s}, d_{s}\right)$ of the seller in the communication stage.

1. If $m_{s}^{1}>m_{b}^{1}$, then the behavioral-type buyer believes that the seller will bid 1 . Thus, the behavioral-type buyer cannot increase her payoff by bidding any value other than 0 .

2. If $m_{s}^{1} \leq m_{b}^{1}$ and $m_{s}^{2}=K$, then the behavioral-type buyer believes that the seller is a behavioral type who will bid $\frac{1}{2}\left(m_{b}^{1}+m_{s}^{1}\right)$ since in equilibrium, only this type of the seller makes such an announcement in the communication stage. Since $m_{s}^{1} \leq m_{b}^{1}=v_{b}$, it is a best response for the behavioral-type buyer to bid equal to $\frac{1}{2}\left(m_{b}^{1}+m_{s}^{1}\right)$.

3. If $m_{s}^{1} \leq m_{b}^{1}$ and $m_{s}^{2}=N K$, then the behavioral-type buyer believes that the seller is a strategic type who will bid $m_{b}^{1}$ in the double auction since only this type of the seller makes such an announcement in the communication stage. Since $m_{s}^{1} \leq m_{b}^{1}=v_{b}$, it is a best response for the behavioral-type buyer to bid equal to $m_{b}^{1}$.

Next, consider the continuation game $\left[\left(m_{b}^{1}, m_{b}^{2}\right),\left(m_{s}^{1}, m_{s}^{2}\right)\right]$ such that $\left(m_{i}^{1}, m_{i}^{2}\right)$ is not used in equilibrium by any type of player $i$. Any type of the seller who finds herself in such a continuation game bids 1 . Thus, irrespective of the belief about the seller's type, the behavioral-type buyer cannot increase her payoff by bidding any value other than 0 .

Finally, consider the continuation game $\left[\left(m_{b}^{1}, m_{b}^{2}\right),\left(m_{s}^{1}, m_{s}^{2}\right)\right]$ such that both messages $\left(m_{b}^{1}, m_{b}^{2}\right)$ and $\left(m_{s}^{1}, m_{s}^{2}\right)$ are used, respectively, by some type $\left(v_{b}^{\prime}, d_{b}^{\prime}\right)$ of the buyer and type $\left(v_{s}^{\prime}, d_{s}^{\prime}\right)$ of the seller in equilibrium but $\left(m_{b}^{1}, m_{b}^{2}\right) \neq\left(v_{b}, K\right)$. For reasons mentioned above, we do not need to be more specific than say that the behavioral-type buyer bids optimally against her belief in such a continuation game.

Case 2: Consider the strategic-type buyer of valuation $v_{b}$.

Let's begin with the final double auction stage. First, consider the continuation game $\left[\left(m_{b}^{1}, m_{b}^{2}\right),\left(m_{s}^{1}, m_{s}^{2}\right)\right]$ such that $\left(m_{b}^{1}, m_{b}^{2}\right)=\left(m^{1}\left(v_{b}\right), N K\right)$ and $\left(m_{s}^{1}, m_{s}^{2}\right)$ is a message used in equilibrium by some type $\left(v_{s}, d_{s}\right)$ of the seller in the communication stage.

1. If $m_{s}^{1}>m_{b}^{1}$, then the strategic-type buyer believes that the seller will bid 1 . Thus, the strategic-type buyer cannot increase her payoff by bidding any value other than 0 . 
2. If $m_{s}^{1} \leq m_{b}^{1}$ and $m_{s}^{2}=K$, then the strategic-type buyer believes that the seller is a behavioral type who will bid $m_{s}^{1}$ since in equilibrium, only this type of the seller makes such an announcement in the communication stage. Now, $m_{b}^{1}=m_{b}^{1}\left(v_{b}\right) \leq v_{b}$ (follows from Lemma 2). Since $m_{s}^{1} \leq m_{b}^{1} \leq v_{b}$, it is a best response for the strategic-type buyer to bid equal to $m_{s}^{1}$.

3. If $m_{s}^{1} \leq m_{b}^{1}$ and $m_{s}^{2}=N K$, then the strategic-type buyer believes that the seller is the strategic type who will bid $\frac{1}{2}\left(m_{b}^{1}+m_{s}^{1}\right)$ since in equilibrium, only this type of the seller makes such an announcement in the communication stage. Now, $m_{b}^{1}=m_{b}^{1}\left(v_{b}\right) \leq v_{b}$ (follows from Lemma 2). Since $m_{s}^{1} \leq m_{b}^{1} \leq v_{b}$, it is a best response for the strategictype buyer to bid equal to $\frac{1}{2}\left(m_{b}^{1}+m_{s}^{1}\right) \leq v_{b}$.

Next, consider the continuation game $\left[\left(m_{b}^{1}, m_{b}^{2}\right),\left(m_{s}^{1}, m_{s}^{2}\right)\right]$ such that $\left(m_{i}^{1}, m_{i}^{2}\right)$ is not used in equilibrium by any type of player $i$. Any type of the seller who finds herself in such a continuation game bids 1 . Thus, irrespective of the belief about the seller's type, the strategic-type buyer cannot increase her payoff by bidding any value other than 0 .

Finally, consider the continuation games $\left[\left(m_{b}^{1}, m_{b}^{2}\right),\left(m_{s}^{1}, m_{s}^{2}\right)\right]$ such that both messages $\left(m_{b}^{1}, m_{b}^{2}\right)$ and $\left(m_{s}^{1}, m_{s}^{2}\right)$ are used, respectively, by some type $\left(v_{b}^{\prime}, d_{b}^{\prime}\right)$ of the buyer and type $\left(v_{s}^{\prime}, d_{s}^{\prime}\right)$ of the seller in equilibrium but $\left(m_{b}^{1}, m_{b}^{2}\right) \neq\left(m^{1}\left(v_{b}\right), N K\right)$. For reasons mentioned above, we do not specify the strategy of the strategic-type buyer in such a continuation game. Instead, we show that the strategic-type buyer of valuation $v_{b}$ cannot increase her expected payoff by imitating any type of the buyer in the communication stage and then playing optimally in the ensuing continuation games.

Suppose the strategic-type buyer of valuation $v_{b}$ deviates in the communication stage to an announcement $\left(m_{b}^{1}, m_{K}^{2}\right) \neq\left(m_{b}^{1}\left(v_{b}\right), N K\right)$.

First we argue that deviating to $\left(v_{b}, m_{b}^{2}\right)$ and then playing optimally in the continuation games gives the strategic-type buyer of valuation $v_{b}$ at least as high expected payoff as deviating to $\left(m_{b}^{1}, m_{b}^{2}\right)$ such that $m_{b}^{1}>v_{b}$ and then playing optimally in the continuation games. Intuitively, announcing $\left(m_{b}^{1}, m_{b}^{2}\right)$ instead of $\left(v_{b}, m_{b}^{2}\right)$ either generates new opportunities to trade at a price higher than $v_{b}$ or increases the bid of the seller; thus it cannot increase the strategic-type buyer's expected payoff. To see this formally, note that the set of messages $\left(\hat{m}_{b}^{1}, \hat{m}_{b}^{2}\right)$ that are not used in equilibrium by any type of the buyer are such that $\hat{m}_{b}^{1} \in(\alpha(\epsilon)+\beta(\epsilon), 1]$ and $\hat{m}_{b}^{2}=N K$ (note that Lemma 2 implies that $1>\alpha(\epsilon)+\beta(\epsilon)$ since $1>\gamma(\epsilon))$. Since $m_{b}^{1}>v_{b}$, it cannot be that the message $\left(v_{b}, m_{b}^{2}\right)$ is not used in equilibrium by any type of the buyer while the message $\left(m_{b}^{1}, m_{b}^{2}\right)$ is used in equilibrium by some type of the buyer. If both messages $\left(v_{b}, m_{b}^{2}\right)$ and $\left(m_{b}^{1}, m_{b}^{2}\right)$ are not used in equilibrium by any type of 
the buyer, then the expected payoffs are 0 from both deviations since any type of the seller will bid 1. If the message $\left(v_{b}, m_{b}^{2}\right)$ is used in equilibrium by some type of the buyer while the message $\left(m_{b}^{1}, m_{b}^{2}\right)$ is not used in equilibrium by any type of the buyer, then the expected payoff from deviating to the latter message is 0 while the expected payoff from deviating to the former message is at least 0 . Finally, suppose both messages $\left(v_{b}, m_{b}^{2}\right)$ and $\left(m_{b}^{1}, m_{b}^{2}\right)$ are used in equilibrium by some types of the buyer in equilibrium.

- If the seller announces $m_{s}^{1}>m_{b}^{1}>v_{b}$, then the seller will bid 1 and hence by bidding optimally, the strategic-type buyer will get 0 in such a continuation game irrespective of whether she announces $m_{b}^{1}$ or $v_{b}$.

- If the seller announces $m_{s}^{1}$ such that $m_{b}^{1} \geq m_{s}^{1}>v_{b}$, then the seller will bid at least $m_{s}^{1}$ in the continuation game. But then it is not optimal for the buyer to trade with the seller and hence, the strategic-type buyer will get 0 in such a continuation game irrespective of whether she announces $m_{b}^{1}$ or $v_{b}$.

- If $m_{b}^{2}=K$ and the seller is a behavioral type who announces $m_{s}^{1} \leq v_{b}<m_{b}^{1}$, then the seller will bid $\frac{1}{2}\left(m_{b}^{1}+m_{s}^{1}\right)$ if the strategic-type buyer announces $\left(m_{b}^{1}, K\right)$ while she will bid a lower value of $\frac{1}{2}\left(v_{b}+m_{s}^{1}\right) \leq v_{b}$ if the strategic-type buyer announces $\left(v_{b}, K\right)$. Thus, the strategic-type buyer would be weakly better-off if she announces $\left(v_{b}, K\right)$.

- If $m_{b}^{2}=K$ and the seller is a strategic type who announces $m_{s}^{1} \leq v_{b}<m_{b}^{1}$, then the seller will bid $m_{b}^{1}$ if the strategic-type buyer announces $\left(m_{b}^{1}, K\right)$ while she will bid a lower value of $v_{b}$ if the strategic-type buyer announces $\left(v_{b}, K\right)$. Thus, by playing optimally, the strategic-type buyer would get 0 in such a continuation game irrespective of whether she announces $m_{b}^{1}$ or $v_{b}$.

- If $m_{b}^{2}=N K$ and the seller is a behavioral type who announces $m_{s}^{1} \leq v_{b}<m_{b}^{1}$, then the seller will bid $m_{s}^{1}$ irrespective of whether the strategic-type buyer announces $\left(m_{b}^{1}, N K\right)$ or $\left(v_{b}, N K\right)$. Thus, irrespective of whether the strategic-type buyer announces $\left(m_{b}^{1}, N K\right)$ or $\left(v_{b}, N K\right)$, the strategic-type buyer, by bidding optimally in such a continuation game, will trade at the price of $m_{s}^{1}$.

- If $m_{b}^{2}=N K$ and the seller is a strategic type who announces $m_{s}^{1} \leq v_{b}<m_{b}^{1}$, then the seller will bid $\frac{1}{2}\left(m_{b}^{1}+m_{s}^{1}\right)$ if the strategic-type buyer announces $\left(m_{b}^{1}, N K\right)$ while she will bid a lower value of $\frac{1}{2}\left(v_{b}+m_{s}^{1}\right) \leq v_{b}$ if the strategic-type buyer announces $\left(v_{b}, N K\right)$. Thus, the strategic-type buyer would be weakly better-off if she announces $\left(v_{b}, N K\right)$. 
Next we argue that the expected payoff of the strategic-type buyer if she follows her equilibrium strategy is at least as high as her expected payoff if she deviates to a message $\left(m_{b}^{1}, m_{b}^{2}\right) \neq\left(m_{b}^{1}\left(v_{b}\right), N K\right)$, where $m_{b}^{1} \leq v_{b}$, and then plays optimally in the continuation games. Combined with the above argument, it implies that the strategic-type buyer cannot gain by deviating in the communication stage.

1. First, suppose $v_{b}<\gamma(\epsilon)$. Then $v_{b}$ is less than $m_{s}^{1}$ of any strategic-type seller. Thus, by following her equilibrium strategy of announcing $\left(v_{b}, N K\right)$, this buyer will not trade with any strategic-type seller while she will trade at price $v_{s}$ if the seller is a behavioral type of valuation $v_{s} \leq v_{b}$ since such a seller announces $m_{s}^{1}=v_{s}$ and then bids truthfully if $m_{b}^{1} \geq m_{s}^{1}$ and $m_{b}^{2}=N K$. Thus, the equilibrium expected payoff of the strategic-type buyer of valuation $v_{b}<\gamma(\epsilon)$ is $\epsilon \int_{0}^{v_{b}}\left(v_{b}-v_{s}\right) d v_{s}=\epsilon \frac{v_{b}^{2}}{2}$.

Now, suppose the strategic-type buyer of valuation $v_{b}$ deviates to an announcement $\left(m_{b}^{1}, N K\right)$, where $m_{b}^{1}<v_{b}$. If the seller is a strategic type, then she announces $m_{s}^{1} \geq$ $\gamma(\epsilon)>v_{b}>m_{b}^{1}$ and thus bids 1 in the continuation game. Hence, our buyer still gets 0 in such a continuation game. Similarly, if the seller is a behavioral-type who announces $m_{s}^{1}>v_{b}>m_{b}^{1}$, then our buyer still gets 0 in the continuation game since the seller bids 1 . However, if the seller is a behavioral type and $m_{b}^{1}<m_{s}^{1} \leq v_{b}$, then our buyer looses the opportunity to gainfully trade with the seller in the continuation game since the seller bids 1 . On the other hand, whenever $m_{s}^{1} \leq m_{b}^{1}<v_{b}$, our buyer still trades with the behavioral-type seller at an unchanged price of $m_{s}^{1}$ by bidding $m_{s}^{1}$, which is optimal against the seller's bid of $m_{s}^{1}$. Hence, she cannot gain by such a deviation.

Next, suppose the strategic-type buyer of valuation $v_{b}$ deviates to an announcement $\left(m_{b}^{1}, K\right)$, where $m_{b}^{1} \leq v_{b}$. If the seller is a strategic type, then she announces $m_{s}^{1} \geq$ $\gamma(\epsilon)>v_{b} \geq m_{b}^{1}$ and thus bids 1 in the continuation game. Hence, our buyer still gets 0 in such a continuation game. Similarly, if the seller is a behavioral-type who announces $m_{s}^{1}>v_{b} \geq m_{b}^{1}$, then our buyer still gets 0 in the continuation game since the seller bids 1 . If $m_{b}^{1}<v_{b}$, the seller is a behavioral type and $m_{b}^{1}<m_{s}^{1} \leq v_{b}$, then our buyer looses the opportunity to gainfully trade with the seller at a price of $m_{s}^{1}$ in the continuation game since the seller now bids 1 . On the other hand, whenever $m_{s}^{1} \leq m_{b}^{1} \leq v_{b}$, then the behavioral-type seller will bid $\frac{1}{2}\left(m_{b}^{1}+m_{s}^{1}\right)$ and thus our buyer trades with the behavioral-type seller at a weakly higher price of $\frac{1}{2}\left(m_{b}^{1}+m_{s}^{1}\right)$ instead of $m_{s}^{1}$. Hence, she cannot gain by such a deviation.

2. Second, suppose $v_{b} \geq \gamma(\epsilon)$. Then by following her equilibrium strategy, she does 
not trade with the strategic-type seller who announces $m_{s}^{1}=v_{s}>\alpha(\epsilon)+\beta(\epsilon) \geq$ $\alpha(\epsilon) v_{b}+\beta(\epsilon)=m_{b}^{1}$. Thus, among the strategic types of the sellers, she only trades with those who announce $m_{s}^{1}=\alpha(\epsilon) v_{s}+\gamma(\epsilon) \leq \alpha(\epsilon) v_{b}+\beta(\epsilon)=m_{b}^{1}$ at the price $\frac{1}{2}\left(m_{b}^{1}+m_{s}^{1}\right)=\frac{1}{2}\left[\alpha(\epsilon) v_{b}+\beta(\epsilon)+\alpha(\epsilon) v_{s}+\gamma(\epsilon)\right]$. Whereas, by following her equilibrium strategy, she will trade at price $v_{s}$ if the seller is a behavioral type of valuation $v_{s} \leq$ $\alpha(\epsilon) v_{b}+\beta(\epsilon)=m_{b}^{1}$ since such a seller announces $m_{s}^{1}=v_{s}$ and then bids truthfully if $m_{b}^{1} \geq m_{s}^{1}$ and $m_{b}^{2}=N K$. Thus, the equilibrium expected payoff of the strategic-type buyer of valuation $v_{b} \geq \gamma(\epsilon)$ is

$(1-\epsilon) \int_{0}^{v_{b}+\frac{\beta(\epsilon)-\gamma(\epsilon)}{\alpha(\epsilon)}}\left\{v_{b}-\frac{1}{2}\left[\alpha(\epsilon) v_{b}+\beta(\epsilon)+\alpha(\epsilon) v_{s}+\gamma(\epsilon)\right]\right\} d v_{s}+\epsilon \int_{0}^{\alpha(\epsilon) v_{b}+\beta(\epsilon)}\left\{v_{b}-v_{s}\right\} d v_{s}$.

Now, suppose the strategic-type buyer of valuation $v_{b}$ deviates to an announcement $\left(m_{b}^{1}, N K\right)$ where $m_{b}^{1} \neq \alpha(\epsilon) v_{b}+\beta(\epsilon)$ and $m_{b}^{1} \leq v_{b}$.

(a) Assume that $m_{b}^{1}<\gamma(\epsilon)$. Then in the continuation games, she does no trade with any strategic-type seller since for such a seller $m_{s}^{1} \geq \gamma(\epsilon)$. By such a deviation, the strategic-type buyer trades only with those behavioral types of the seller of valuations $v_{s} \leq m_{b}^{1}$ at the price $m_{s}^{1}=v_{s}$ since such a seller announces $m_{s}^{1}=v_{s}$ and then bids truthfully if $m_{b}^{1} \geq m_{s}^{1}$ and $m_{b}^{2}=N K$. But our strategic-type buyer is able to trade with such a behavioral-type seller at the price of $v_{s}$ even if she announces her equilibrium message $\alpha(\epsilon) v_{b}+\beta(\epsilon)>m_{b}^{1}$. Therefore, she cannot gain by such a deviation.

(b) Assume that $\gamma(\epsilon) \leq m_{b}^{1} \leq \min \left\{v_{b}, \alpha(\epsilon)+\beta(\epsilon)\right\}$. Then in the continuation games, she does not trade with the strategic-type seller who announces $m_{s}^{1}=v_{s}>\alpha(\epsilon)+$ $\beta(\epsilon) \geq \alpha(\epsilon) v_{b}+\beta(\epsilon) \geq m_{b}^{1}$. In the continuation games, she trades only with those strategic types of the seller who announce $m_{s}^{1}=\alpha(\epsilon) v_{s}+\gamma(\epsilon) \leq m_{b}^{1}$ at the price $\frac{1}{2}\left[m_{b}^{1}+\alpha(\epsilon) v_{s}+\gamma(\epsilon)\right]$ since such a seller bids $\frac{1}{2}\left(m_{b}^{1}+m_{s}^{1}\right)$ if $m_{s}^{1} \leq m_{b}^{1}$ and $m_{b}^{2}=N K$. In the continuation games, our strategic-type buyer also trades with only those behavioral types of the seller of valuations $v_{s} \leq m_{b}^{1}$ at price $v_{s}$ since such a seller announces $m_{s}^{1}=v_{s}$ and then bids truthfully if $m_{b}^{1} \geq m_{s}^{1}$ and $m_{b}^{2}=N K$. Therefore, the expected payoff of our strategic-type buyer from this deviation is

$U\left(m_{b}^{1}\right) \equiv(1-\epsilon) \int_{0}^{\frac{m_{b}^{1}-\gamma(\epsilon)}{\alpha(\epsilon)}}\left\{v_{b}-\frac{1}{2}\left[m_{b}^{1}+\alpha(\epsilon) v_{s}+\gamma(\epsilon)\right]\right\} d v_{s}+\epsilon \int_{0}^{m_{b}^{1}}\left\{v_{b}-v_{s}\right\} d v_{s}$. 
Maximizing $U\left(m_{b}^{1}\right)$ with respect to $m_{b}^{1}$, we get that

$$
\begin{aligned}
m_{b}^{1} & =\frac{2(1-\epsilon)+2 \epsilon \alpha(\epsilon)}{3(1-\epsilon)+2 \epsilon \alpha(\epsilon)} v_{b}+\frac{(1-\epsilon) \gamma(\epsilon)}{3(1-\epsilon)+2 \epsilon \alpha(\epsilon)} \\
& =\alpha(\epsilon) v_{b}+\beta(\epsilon),
\end{aligned}
$$

where $\frac{2(1-\epsilon)+2 \epsilon \alpha(\epsilon)}{3(1-\epsilon)+2 \epsilon \alpha(\epsilon)}=\alpha(\epsilon)$ since $\alpha(\epsilon)$ is the root of the quadratic equation $2 \epsilon[\alpha(\epsilon)]^{2}-$ $(5 \epsilon-3) \alpha(\epsilon)-2(1-\epsilon)=0$. Thus, we have a contradiction.

(c) Assume that $v_{b} \geq m_{b}^{1}>\alpha(\epsilon)+\beta(\epsilon)$. Then our strategic buyer is deviating to a message that is not used in equilibrium by any type of the buyer. Thus, any type of the seller will bid 1 in the continuation game and so our buyer will not be able to trade. Hence, she cannot gain by such a deviation.

Next, suppose the strategic-type buyer of valuation $v_{b}$ deviates to an announcement $\left(m_{b}^{1}, K\right)$ where $m_{b}^{1} \leq v_{b}$.

(a) Assume that $m_{b}^{1}<\gamma(\epsilon)$. Then in the continuation games, she does no trade with any strategic-type seller since for such a seller $m_{s}^{1} \geq \gamma(\epsilon)$. By such a deviation, the strategic-type buyer trades only with those behavioral types of the seller of valuations $v_{s} \leq m_{b}^{1}$ at the price $\frac{1}{2}\left(m_{b}^{1}+m_{s}^{1}\right) \geq v_{s}$ since such a seller announces $m_{s}^{1}=v_{s}$ and then bids $\frac{1}{2}\left(m_{b}^{1}+m_{s}^{1}\right)$ if $m_{b}^{1} \geq m_{s}^{1}$ and $m_{b}^{2}=K$. But our strategictype buyer is able to trade with such a behavioral-type seller at the price of $v_{s}$ if she announces her equilibrium message $\alpha(\epsilon) v_{b}+\beta(\epsilon)>m_{b}^{1}$. Therefore, she cannot gain by such a deviation.

(b) Assume that $\gamma(\epsilon) \leq m_{b}^{1} \leq \min \left\{v_{b}, \alpha(\epsilon)+\beta(\epsilon)\right\}$. Then in the continuation games, she does not trade with the strategic-type seller who announces $m_{s}^{1}=v_{s}>\alpha(\epsilon)+$ $\beta(\epsilon) \geq \alpha(\epsilon) v_{b}+\beta(\epsilon) \geq m_{b}^{1}$. In the continuation games, she trades only with those strategic types of the seller who announce $m_{s}^{1}=\alpha(\epsilon) v_{s}+\gamma(\epsilon) \leq m_{b}^{1}$ at the price $m_{b}^{1}$ since such a seller bids $m_{b}^{1}$ if $m_{s}^{1} \leq m_{b}^{1}$ and $m_{b}^{2}=K$. In the continuation games, our strategic-type buyer also trades with only those behavioral types of the seller of valuations $v_{s} \leq m_{b}^{1}$ at the price $\frac{1}{2}\left(m_{b}^{1}+v_{s}\right)$ since such a seller announces $m_{s}^{1}=v_{s}$ and then bids $\frac{1}{2}\left(m_{b}^{1}+v_{s}\right)$ if $m_{b}^{1} \geq m_{s}^{1}$ and $m_{b}^{2}=K$. If the strategictype buyer had instead announced $\left[m_{b}^{1}, N K\right]$, then she would have traded with all those strategic types of the seller who announce $m_{s}^{1}=\alpha(\epsilon) v_{s}+\gamma(\epsilon) \leq m_{b}^{1}$ at the price $\frac{1}{2}\left(m_{b}^{1}+m_{s}^{1}\right) \leq m_{b}^{1}$ since such a seller bids $\frac{1}{2}\left(m_{b}^{1}+m_{s}^{1}\right)$ if $m_{s}^{1} \leq m_{b}^{1}$ and $m_{b}^{2}=N K$ and with all those behavioral types of the seller of valuations $v_{s} \leq m_{b}^{1}$ 
at the price $v_{s} \leq \frac{1}{2}\left(m_{b}^{1}+v_{s}\right)$ since such a seller announces $m_{s}^{1}=v_{s}$ and then bids $v_{s}$ if $m_{b}^{1} \geq m_{s}^{1}$ and $m_{b}^{2}=N K$. Thus, whenever $\gamma(\epsilon) \leq m_{b}^{1} \leq \min \left\{v_{b}, \alpha(\epsilon)+\beta(\epsilon)\right\}$, the strategic-type buyer's expected payoff if she announces $\left[m_{b}^{1}, N K\right]$ is weakly higher than her expected payoff if she announces $\left[m_{b}^{1}, K\right]$. But we have already argued above that the strategic-type buyer cannot gain by deviating to $\left[m_{b}^{1}, N K\right]$, where $\gamma(\epsilon) \leq m_{b}^{1} \leq \min \left\{v_{b}, \alpha(\epsilon)+\beta(\epsilon)\right\}$.

(c) Assume that $\alpha(\epsilon)+\beta(\epsilon)<m_{b}^{1} \leq v_{b}$. Then in the continuation games, she does not trade with any strategic-type seller of valuation $v_{s}>m_{b}^{1}$ since such a strategic-type seller announce $m_{s}^{1}=v_{s}$ in the communication stage. In the continuation games, she trades with all those strategic types of the seller whose valuation $v_{s} \leq m_{b}^{1}$ because if $v_{s} \leq \alpha(\epsilon)+\beta(\epsilon)$, then $m_{s}^{1}=\alpha(\epsilon) v_{s}+\gamma(\epsilon) \leq \alpha(\epsilon)+\beta(\epsilon)$ (follows from Lemma 3) while if $v_{s}>\alpha(\epsilon)+\beta(\epsilon)$, then $m_{s}^{1}=v_{s}$. Moreover, she trades with all such strategic types of the seller at the price of $m_{b}^{1}$ since such a seller bids $m_{b}^{1}$ if $m_{s}^{1} \leq m_{b}^{1}$ and $m_{b}^{2}=K$. In the continuation games, she also trades with only those behavioral types of the seller of valuations $v_{s} \leq m_{b}^{1}$ at the price $\frac{1}{2}\left(m_{b}^{1}+v_{s}\right)$ since such a seller announces $m_{s}^{1}=v_{s}$ and then bids $\frac{1}{2}\left(m_{b}^{1}+v_{s}\right)$ if $m_{b}^{1} \geq m_{s}^{1}$ and $m_{b}^{2}=K$. Therefore, the expected payoff of our strategic-type buyer from this deviation is

$$
V\left(m_{b}^{1}\right) \equiv(1-\epsilon) \int_{0}^{m_{b}^{1}}\left\{v_{b}-m_{b}^{1}\right\} d v_{s}+\epsilon \int_{0}^{m_{b}^{1}}\left\{v_{b}-\frac{1}{2}\left(m_{b}^{1}+v_{s}\right)\right\} d v_{s} .
$$

Taking the derivative of $V\left(m_{b}^{1}\right)$ with respect to $m_{b}^{1}$, we get that

$$
V^{\prime}\left(m_{b}^{1}\right)=(1-\epsilon)\left(v_{b}-2 m_{b}^{1}\right)+\epsilon\left(v_{b}-\frac{3}{2} m_{b}^{1}\right)<0
$$

where the inequality follows from the fact that $m_{b}^{1}>\alpha(\epsilon)+\beta(\epsilon)>\frac{2}{3}$. Therefore, $V(\alpha(\epsilon)+\beta(\epsilon))>V\left(m_{b}^{1}\right)$. But $V(\alpha(\epsilon)+\beta(\epsilon))$ is the expected payoff of the strategic-type buyer of valuation $v_{b}$ if she deviates to $(\alpha(\epsilon)+\beta(\epsilon), K)$ and we have already argued that she cannot gain over her equilibrium expected payoff by such a deviation.

Proof of Corollary 1: The corollary follows since $\gamma(\epsilon)<\frac{1}{4}, \alpha(\epsilon) v_{b}+\beta(\epsilon)>v_{b}-\frac{1}{4}$ and $v_{s}+\frac{1}{4}>\alpha(\epsilon) v_{s}+\gamma(\epsilon)$. 


\section{References}

Abreu D, Gul F (2000) Bargaining and reputation. Econometrica 68: 85-117

Ausubel L, Cramton P, Deneckere R (2002) Bargaining with incomplete information. In: Aumann R, Hart S (eds.) Handbook of game theory with economic applications 3. NorthHolland, Amsterdam, 1897-1946

Binmore K, Osborne M, Rubinstein A (1992) Noncooperative models of bargaining. In: Aumann R, Hart S (eds.) Handbook of game theory with economic applications 1. NorthHolland, Amsterdam, 179-225

Chatterjee K, Samuelson W (1983) Bargaining under incomplete information. Operations Research 31: 835-851

P. Dasgupta P (1988) Trust as a commodity. In: Gambetta D (ed.) Trust: making and breaking cooperative relations. Basil Blackwell, Oxford, 49-72.

Farrell J, Gibbons R (1989) Cheap talk can matter in bargaining. Journal of Economic Theory 48: 221-237

Fudenberg D, Tirole J (1991). Game Theory. MIT Press, Cambridge

Hoffman E, Spitzer M (1982). The coase theorem: some experimental tests. Journal of Law and Economics 25: 9398

Kennan J, Wilson R (1993) Bargaining with private information. Journal of Economic Literature 31: 45-104

Kreps D, Milgrom P, Roberts J, Wilson R (1982) Rational cooperation in the finitely repeated Prisoner's Dilemma. Journal of Economic Theory 27: 245-252

Kreps D, Wilson R (1982) Reputation and imperfect information. Journal of Economic Theory 27: $253-279$

Leininger W, Linhart P, Radner R (1989) Equilibria of the sealed-bid mechanism for bargaining with incomplete information. Journal of Economic Theory 48: 63-106

Lundquist T, Ellingsen T, Gribbe E, Johannesson M (2009). The aversion to lying. Journal of Economic Behavior and Organization 70: 81-92 
Mathews S, Postlewaite A (1989) Pre-play communication in two-person sealed-bid double auctions. Journal of Economic Theory 48: 238-263.

Manzini P, Sadrieh A, Vriend N J (2009) On smiles, winks and handshakes as coordination devices. Economic Journal 119: 826854.

McGinn K, Thompson L, Bazerman M (2003) Dyadic processes of disclosure and reciprocity in bargaining with communication. Journal of Behavioral Decision Making 16: 17-34

Milgrom P, Roberts J (1982) Predation, reputation and entry deterrence. Journal of Economic Theory 27: 280-312

Myerson R, Satterthwaite M (1983) Efficient mechanisms for bilateral trading. Journal of Economic Theory 29: 265-281

Osborne M, Rubinstein A (1990) Bargaining and markets. Academic Press, San Diego

Radner R, Schotter A (1989) The sealed-bid mechanism: an experimental study. Journal of Economic Theory 48: 179-220

Satterthwaite M, Williams S (1989) Bilateral trade with the sealed bid $k$-double auction: existence and efficiency. Journal of Economic Theory 48: 107-133

Serrano R (2008) Bargaining. In: Durlauf S, Blume L (eds.) The new Palgrave dictionary of economics 2. McMillan, London

Saran R (2008) In bargaining we trust. Mimeo, Maastricht University.

Severinov S, Deneckere R (2006) Screening when not all agents are strategic: Does a monopoly need to exclude? RAND Journal of Economics 37: 816-841.

Sobel J (1985) A theory of credibility. Review of Economic Studies 52: 557-573

Valley K L, Moag J, Bazerman M H (1998). A matter of trust: effects of communication on the efficiency and distribution of outcomes. Journal of Economic Behavior and Organization 34: 211238.

Valley K, Thompson L, Gibbons R, Bazerman M (2002) How communication improves efficiency in bargaining games. Games and Economic Behavior 38: 127-155

Williams S (1987), Efficient performance in two agent bargaining. Journal of Economic Theory 41: 154-172 